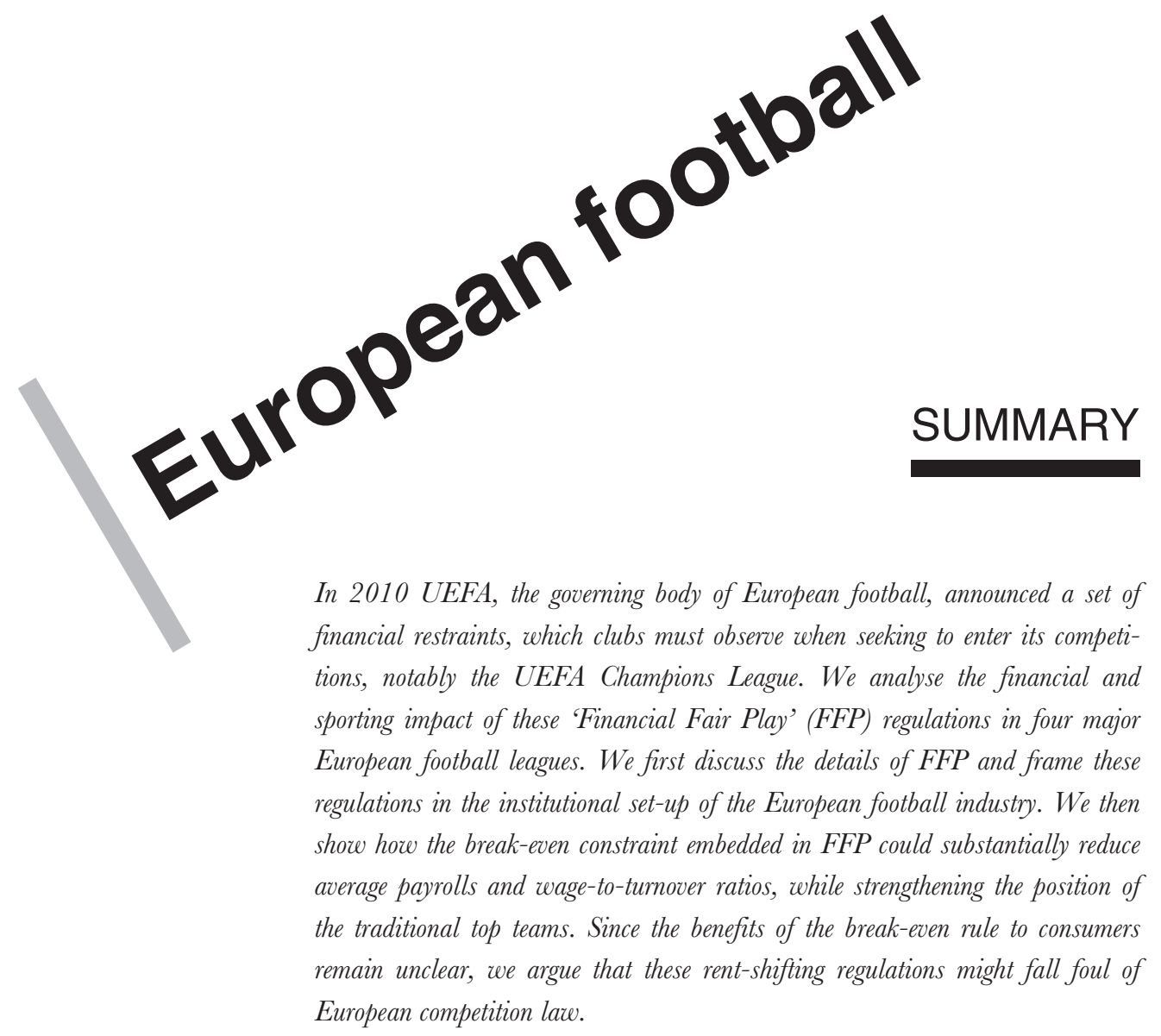

— Thomas Peeters and Stefan Szymanski 



\section{Financial fair play in European football}

\section{Thomas Peeters and Stefan Szymanski}

University of Antwerp and Flanders Research Foundation (FWO); University of Michigan

\section{INTRODUCTION}

Football is by far the most popular sport in the world. The sport's origins are European, and European professional football has dominated the sport. The biggest leagues and clubs are in Europe; Europe produces most of the top players and those that are not European are attracted to play in Europe by means of high salaries. Despite this, European football clubs have seldom been profitable ventures, and financial crises have been commonplace. In the last two decades the development of broadcasting technologies has expanded the reach and increased the income levels of European clubs at an extraordinary rate, and yet the financial state of European professional clubs seems, if anything, to have deteriorated. In 2010 UEFA, the governing body of European football, announced a set of regulations, known as 'Financial Fair Play' (FFP), intended to bring 'discipline and rationality' to European football club finances.

The authors would like to thank three anonymous referees, the editor, our panel discussants, Chiara Fumagalli and Catherine Thomas and participants at the Economic Policy Panel in Vilnius, as well as Egon Franck, Stephen F. Ross, Stefan Késenne, Jan Bouckaert, Jo Swinnen and seminar participants at the ESEA conference in Esbjerg, the 3rd Conference on contests, tournaments and relative performance evaluation at UC Merced, the University of Maryland Baltimore County, Leuven, Antwerp and Groningen for valuable comments and suggestions. We further thank Alberto Alvisi, Bastien Drut and Angel Barajas for valuable help in bringing the dataset together. Peeters gratefully acknowledges financial support from the Flanders Research Foundation (FWO).

The Managing Editor in charge of this paper was Nicola Fuchs-Schündeln. 
The most controversial aspect of the FFP regulations is the break-even rule, which limits team spending on player wages and transfers to their revenues obtained from 'football related activities'. Crucially, this rules out investments in playing talent financed directly by team owners, which is a major source of funding for a string of high-profile clubs with benefactor owners. ${ }^{1}$ It seems inevitable, therefore, that several teams will have to cut back player wages when the FFP rules come into full effect. The break-even rule obviously runs against the interests of players and agents (who earn a portion of whatever players are making), and one would expect legal challenges against the FFP regulations on their behalf. It came as no surprise, then, that on 6 May 2013 Belgian competition lawyer Jean-Louis Dupont, who pleaded successfully to abolish UEFA's transfer system in the 1995 Bosman ruling (ECR I-4921), filed a complaint with the European Commission on behalf of Daniel Striani (a player agent) challenging the legality of the break-even rule under EU law. Mr Dupont argues in his complaint that:

The 'Break-even' rule (which according to article 101 of the Treaty on the functioning of the EU, is an 'agreement between undertakings') generates the following restrictions of competition:

- Restriction of investments;

- Fossilization of the existing market structure (i.e. the current top clubs are likely to maintain their leadership and even increase it);

- Reduction of the number of transfers, of the transfer amounts and of the number of players under contracts per club;

- Deflatory effect on the level of player's salaries; and

- Consequently, a deflatory effect on the revenues of players' agents. (Dupont, 2013, p. 1)

In Mr Dupont's view the break-even rule constitutes a restraint on competition, which infringes on the free movement of capital, workers and services. He further argues that the rule is not only unjustifiable, but also in practice illegal, because the rule is not proportionate (since it can be replaced by another measure, equally efficient but less damaging as far as EU freedoms are concerned)' (Dupont, 2013, p. 2).

It is important to note that spending limits have regularly been imposed on clubs in professional leagues in the US, but always on the grounds that these will enhance the competitive balance of the league, and thus bring benefits to consumers in terms of a more attractive competition, as well as restraining costs to the benefit of owners. Even though courts in Europe have recognized that competitive balance might be a legitimate rationale for regulating sporting activities, UEFA has never officially put forward a balance rationale for the break-even rule.

\footnotetext{
${ }^{1}$ Famous examples include Chelsea and Manchester City of England and PSG and Monaco of France.
} 
The purpose of this paper is to shed light on the compatibility of Financial Fair Play with EU law by investigating the implications of the break-even rule for the finances and sports results of European clubs. To do this we simulate its impact on four of the largest leagues in Europe - England, France, Italy and Spain - under the assumption that the regulations had applied to the 2010 or 2011 season. We show that the break-even rule is likely to increase the profitability of clubs largely by reducing wage spending, which supports the claims made in the complaint filed by Mr Dupont. Our analysis further reveals that a US-style explicit salary cap would be a far more effective tool to improve the seasonal competitive balance in European football than the FFP regulations. Furthermore, FFP is bound to cement the competitive advantages of incumbent top teams, because it essentially rules out challenges to their position by clubs which are bankrolled by wealthy investors. These findings render a justification of the break-even rule on competitive balance grounds problematic. We therefore argue that, unlike salary caps in the US sports regime which have evaded competition law sanction, the FFP rules which restrain spending are likely to fall foul of EU competition law.

The next section looks at the institutional framework of sports leagues in North America and Europe. The following section examines the FFP regulation in more detail and looks into the rationale behind the FFP rules. We then explain how FFP's break-even rule operates in a stylized theoretical model, and estimate its effect empirically. A final section provides some conclusions.

\section{THE REGULATION OF PROFESSIONAL SPORTS LEAGUES}

In a league competition teams play each other according to a schedule over a season with a view to determining which is the best team - the champions. Teams are thus competitors in a sporting sense, but need not necessarily be considered rivals in a commercial sense. Viewed as a production activity, each team cannot even create a match without the cooperation of a rival team, as each team needs its competitors to complete their schedule of games in order to produce a league championship. Cooperation between sporting competitors is needed to agree on the rules of the game, scheduling and so on. Leagues cannot therefore be treated as cartels whose agreements are illegal per se. Nonetheless, the appropriate treatment of sports leagues under competition law has been controversial almost from their inception.

One school of thought, associated with Gary Roberts (see Roberts, 1984), argues that sports leagues are 'single entities', analogous to the subsidiaries of a holding company and therefore exempt from cartel laws (collusion requires an agreement between at least two fully independent entities). This view was decisively rejected in 2010 by the US Supreme Court in the American Needle case, which held that teams in the 
National Football League (NFL) are not only sporting competitors but also competitors to attract fans. ${ }^{2}$ The European courts have adopted a similar position.

Despite some organizational similarities, there are key differences between the American model of professional league competition and the model adopted in Europe (and most of the world) for football competition. ${ }^{3}$

\subsection{The American closed league model}

The oldest surviving league in the world, baseball's National League, was established as a collection of city franchises, each granted an exclusive territory, a practice followed by professional leagues in all other US sports. ${ }^{4}$ While new franchises can be admitted with the agreement of existing members, this is a purely commercial decision and entry fees can be upwards of $\$ 1$ billion. Franchise owners are considered to be profit maximizers, and the league is run collectively by the franchises. Unlike most of the rest of the world, they are not answerable to governing bodies which oversee the sport as a whole. Each league may have a Commissioner who coordinates policy, but he is hired, and can be fired, by a vote of the franchises owners.

From an economic perspective the central issue for the major leagues has been the imposition of economic restraints and their motivation. In 1879 the National League adopted the Reserve Clause, which essentially tied players to their club so long as they wished to play within the league (initially players were able to move freely to any of the lesser baseball leagues but later agreements eliminated this opportunity as well). Since that time restraints adopted by the major leagues include:

1. Roster limits (maximum number of players per team)

2. Salary caps (limiting wage spending)

3. Draft rules (restricting the right to recruit players)

4. Gate revenue sharing (allocating a fixed percentage to the visiting team)

\footnotetext{
2 The case concerned the selling of intellectual property produced by teams under the name of the NFL. The court held 'Any joint venture involves multiple sources of economic power cooperating to produce a product. And for many such ventures, the participation of others is necessary. But that does not mean that necessity of cooperation transforms concerted action into independent action; a nut and a bolt can only operate together, but an agreement between nut and bolt manufacturers is still subject to section 1 analysis.' Note that section 1 of the Sherman Act deals with cartel agreements (see American Needle, Inc. $v$. National Football League, p. 14.)

3 The comparison of the two models is discussed extensively in Hoehn and Szymanski (1999) and Szymanski (2003).

4 The 'Major leagues' today consist of the Major League Baseball (MLB), which is itself comprised of the National League and the American League, the National Football League (NFL), the National Basketball Association (NBA) and the National Hockey League (NHL); Major League Soccer (MLS) was established in 1998 but does not yet command the same following as the other major leagues.
} 
5. Collective selling of broadcast rights (proceeds from which are then divided equally between the teams)

6. Collective selling of merchandising (again, proceeds are divided equally).

All of these restraints have been justified by the leagues in the name of competitive balance. According to this argument, unless resources are divided relatively equally among the teams the league will tend to be dominated by only a few teams (especially those from the larger cities which can generate more income) and as a result fans will lose interest, and even the larger teams will suffer. The greater the uncertainty of outcome, it is argued, the more attractive the contest and therefore the greater fan interest in the league. ${ }^{5}$

Against this, it has been widely argued that restraints are also likely to increase the profitability of clubs in the league, irrespective of their impact on competitive balance, since they will reduce competition for players either directly (e.g. draft rules allocate exclusive bargaining rights for a given player to a single team) or indirectly (if revenues are increasing in wins, at least up to some point, then revenue sharing reduces the returns to winning and hence the incentive to hire better players). In a famous article which pre-figured the Coase Theorem, Simon Rottenberg (1956) argued that the reserve clause only affected the ownership rights over a player's marginal revenue product, and did nothing to affect the distribution of playing talent in the league. Whether players are free agents or owned by their teams, the same incentive exists for players to move or be moved to where their marginal revenue product is greatest. The only difference is that under the reserve clause any rents must accrue to the club rather than the player, who will obtain the rent under free agency.

These arguments have played out extensively in the US courts. Whether upheld or rejected, however, it is clear that these restraints are horizontal in nature - they are agreements among the franchises intended to further their own best interests. The situation with European professional football leagues is quite different.

\subsection{The European football model}

Four key differences between the American and European leagues stand out.

2.2.1. Governance. The governance system of European football is hierarchical, sometimes described as a pyramid, where international governing bodies (UEFA and the worldwide football association FIFA) sit at the top, beneath them are their national member associations, with professional leagues and their member clubs sitting below them, and below that lies a whole range of amateur and recreational

\footnotetext{
5 There is a large literature on the relationship between competitive balance and demand both in theory (see e.g. Szymanski, 2001) and empirically (see e.g. Borland and MacDonald, 2003; Garcia and Rodriguez, 2002).
} 
football. One of the earliest principles of this model, going back to the 19th century, is that clubs must be affiliated to and players must be registered with the national association. They must accept its laws, and may not engage in competition with clubs and players that are not affiliated or registered with the association. As well as enforcing a standardized set of rules the governing bodies also impose rules concerning the transfer of players in order to limit opportunistic behaviour (e.g. to prevent successful teams temporarily hiring players from less successful rivals towards the end of a championship in order to secure victory).

\section{Box 1 Club licensing and the growth of UEFA}

UEFA was founded as an organization in 1954 primarily to organize the Cup competition that has now evolved into the Champions League. It also administers a number of smaller club and youth competitions, as well as the European Championship (Euros) in which national teams compete. Its membership consists of the national governing bodies of football in Europe (broadly defined to include nations such as Azerbaijan and Israel). It currently has 54 members, most of whom are within the European Union.

Even though not all UEFA's members lie within the European Union, UEFA's role as a coordinator of national regulations grew out of the tension between European law and football regulations. While national associations have argued that sporting rules lie beyond the jurisdiction of governments and courts, the European Court of Justice asserted as early as 1974 that 'sport is subject to Community law', but 'only insofar as it constitutes an economic activity'. For example, the Bosman case (1995) which ruled that the player transfer system contravened EU law, forced national associations to adopt a system compatible with the free movement of labour within the EU.

In 1999 UEFA decided to embark on a system of licensing for clubs entering UEFA competitions. According to UEFA, initially the purpose was to explore the possibility of creating a salary cap, but it was soon decided that this could not be done without first creating a legal framework. The rules of the licensing system are laid down by UEFA, and the award of the licences is overseen by the national associations so as to bring 'member associations closer to their clubs'. Initially the licensing system laid down rules relating to sporting development (youth training), infrastructure (stadiums), personnel and administration (key posts to be filled), legal (documentation) and financial issues. The financial requirements were for the provision of periodic audited financial statements, and that clubs should have no 'overdue payables' to other clubs or players. These requirements were applied from the 2004/05 season, and extended in 2008/09 season to include no overdue payment to tax authorities and provision of budget forecasts. In 2009 UEFA also announced the introduction of Financial Fair Play. 
UEFA has grown in part because of the escalating value of broadcast rights for the competitions it administers (annual income is currently around $€ 1.5$ billion), but also because of its increasing role in regulation. Some welcome this expansion as a form of harmonization of regulatory systems, while others may view this as an unwarranted centralization of regulatory power.

National and international associations act not only as guardians of the rules and disciplinary procedures, but also as competition organizers. In most countries there is a domestic cup competition run by the national association in which the top clubs participate. In some countries the league is an independent entity affiliated with the national association, in others the national association directly runs the professional league. The national association also runs the national team and clubs are obliged to release their employees for this purpose without compensation (the players themselves usually receive some payment). UEFA and FIFA also combine their role as regulators and promoters of football with the organization of international club competitions (e.g. the Champions and Europa League) and national team tournaments (e.g. the Euro Cup for UEFA and the World Cup for FIFA). We describe the historic development of UEFA and club licensing in more detail in Box 1.

2.2.2. Promotion and relegation. A key feature of the competition structure in football is the promotion and relegation system. Each league within a country has a place in the hierarchy, and at the end of the season the best performing teams in the league are promoted to play the next season at the next highest league, changing places with the worst performing teams from that league (the relegated clubs). Traditionally promotion is purely a function of sporting merit. ${ }^{6}$ There are no exclusive territories in the football model, and so in principle a group of individuals can start a team anywhere they like, and through promotion rise to the highest level of competition.

2.2.3. Multiple competitions. In the closed league system of North America clubs are committed to playing exclusively against teams within the league they belong to, and each league plays a single championship each season. If the clubs choose to do so players may be released to play for national teams, but this is much less frequently observed than in the football world. There, clubs may participate in as many as five competitions in a single season - a domestic league, one or two domestic cup (knockout) competitions and a European-wide cup competition - currently the UEFA-organized Champions League or Europa League. The standard of competition can vary substantially. For example, the quality of players in a team such as FC Porto of Portugal is such that they have won their domestic league in 8 of the last 10 seasons, but

\footnotetext{
${ }^{6}$ A hierarchy of leagues exists in the closed North American system as well, and while players may move clubs and thus go up in the hierarchy, the clubs remain at the same level.
} 
since winning the Champions League 10 years ago, they have progressed beyond the last 16 in the tournament only once.

2.2.4. Not businesses (?). Few question whether the owners of North American franchises are profit maximizers, but there are good reasons to doubt this characterization when applied to European football clubs. In almost every case clubs started as member associations with a non-profit objective of playing sport. In some countries such as the UK, professional clubs have been limited liability companies since the 19th century, but even they were prohibited from paying dividends or paying a salary to company directors until the 1980s. Since then some clubs have floated on the stock exchange and there is a perception that their owners are more profit oriented. In other countries, however, clubs often remain as member associations, most notably Barcelona and Real Madrid, which along with Manchester United generate the largest income of any football clubs in the world and have a global following. Most clubs in Germany are also member controlled associations. ${ }^{7}$ Several countries (such as France and Spain) have specific laws which give special status to club companies while restricting their powers to distribute profits to shareholders. For many fans it is important that their club is not a business, but a community asset. ${ }^{8}$

\section{FINANCIAL FAIR PLAY}

\subsection{A detailed overview}

Financial Fair Play (FFP) is the name given by UEFA to a system of financial regulation which was introduced in 2010 and will come fully into force at the end of the 2013/14 football season (the most recent version of the regulations is UEFA, 2012b).

Any club that wishes to take part in UEFA's two main competitions, the Champions League and Europa League, must obtain a licence from their national association certifying that they meet certain criteria. The key criteria are:

1. No overdue payables. This means that a club must be fully up to date with payments to creditors.

2. Break-even. This means that a club must be able to demonstrate that 'relevant' income balances with 'relevant' expenditure. For these purposes the balance of income and expenditure are calculated over a three-year period, and the balance

\footnotetext{
${ }^{7}$ According to UEFA, in $201132 \%$ of European clubs are organized as member associations, $28 \%$ as company based entities (excluding listed companies), 22\% as sporting incorporated entities, $8 \%$ as not-forprofits, $8 \%$ were listed on a stock exchange and $2 \%$ were state funded entities.

${ }^{8}$ Supporters Direct, a European-wide organization founded in 2000 and funded in part by UEFA, the European Commission, the UK and other governments, exists specifically 'to promote sustainable spectator sports clubs based on supporters' involvement and community ownership'. See more at: http:// www.supporters-direct.org/homepage/aboutsupportersdirect/mission-statement\#sthash.knhW4D3P.dpuf
} 
is subject to an acceptable deviation of $€ 5$ million. Moreover, there is a transitional period to 2018 during which larger deviations are permitted.

The break-even constraint is complex, since allowable income and expenditures are defined in great detail. They do not coincide with simple accounting definitions and a club could in theory declare an accounting profit while failing to meet break-even or declare an accounting loss but meet break-even. 'Relevant' or 'football' income is broadly defined as income from ticket sales, merchandising, broadcasting rights and sponsorship. Football expenditure is broadly defined as wage and transfer spending on players.

Because club success is often viewed as a source of national prestige, a potential enforcement problem for UEFA is collusion between the national association responsible for awarding the licence and their member clubs. UEFA has therefore established the Club Financial Control Panel (CFCP) to oversee the monitoring process, audit the decisions of the national association and challenge them where this is deemed appropriate. Challenges to national decisions are then adjudicated by an appeals body. Of particular concern is that clubs might attempt to evade the system by creative accounting. For example, Manchester City is currently sponsored by Etihad Airways, the national carrier of the United Arab Emirates (UAE). It has been alleged that the payment to Manchester City is well in excess of the market rate, thus allowing Sheikh Mansour, who is deputy Prime Minister of the UAE and whose family controls the airline, to give the appearance that the 'relevant income' of the club is larger than it really is and therefore bring the club closer to break-even. The GFCP has the power to determine whether the contract represents 'fair value' and, if not, to adjust the break-even figures accordingly.

The effectiveness of FFP is likely to rest on the credibility of the sanctions applied. UEFA has a wide variety of sanctions it can apply, ranging from a mere reprimand to exclusion from UEFA competition. Most fans, who seem generally to favour FFP, expect that clubs that fail to meet the FFP criteria will be excluded, and in fact in the last decade 37 clubs have been excluded from competition on the grounds of failing to meet other UEFA licensing conditions. However, these clubs have mostly been small and not from powerful national associations. ${ }^{9}$ If more famous clubs fail to meet the criteria UEFA may be reluctant to punish them too harshly for fear that their exclusion will reduce the attractiveness of the competition. Moreover, if too many clubs are excluded they might decide to form their own rival competition. This credibility problem may have already undermined the regulations, since UEFA estimated that 13 clubs would have failed to meet the criteria if they had applied in 2011, up from 7 in each of the previous two years.

\footnotetext{
${ }^{9}$ One-quarter of the exclusions applied to teams from Kazakhstan alone and only two cases related to clubs from the 'big 5' leagues (England, France, Germany, Italy and Spain). See Union of European Football Associations (UEFA) (2012a).
} 


\subsection{The rationale behind Financial Fair Play}

Both the no overdue payables and break-even rules are restraints placed on the commercial activities of clubs seeking to participate in UEFA competition. In the American model, restraints are horizontal in nature - they are agreements among economic competitors operating at the same level. FFP could be considered a horizontal restraint if it is argued that the clubs approached UEFA and asked them to impose this agreement on their behalf. In reality, however, FFP was initiated by UEFA itself, acting as the regulator for clubs that participate in its competitions, and should therefore be considered as a form of vertical restraint. The motivation for UEFA to implement these regulations has been the subject of some controversy. The official position of UEFA is that:

they aim to achieve financial fair play in UEFA club competitions and in particular:

a) to improve the economic and financial capability of the clubs, increasing their transparency and credibility;

b) to place the necessary importance on the protection of creditors and to ensure that clubs settle their liabilities with players, social/tax authorities and other clubs punctually;

c) to introduce more discipline and rationality in club football finances;

d) to encourage clubs to operate on the basis of their own revenues;

e) to encourage responsible spending for the long-term benefit of football;

f) to protect the long-term viability and sustainability of European club football. (Union of European Football Associations (UEFA), 2012b, p. 2)

This seems a somewhat unsatisfactory motivation to explain the breadth and depth of the enacted regulation, so we consider four alternative rationales for UEFA's adoption of FFP.

3.2.1. Regulating financial instability. The explanation advanced by UEFA implies that it is fulfilling its role as a regulator and imposing rules that will promote the financial health of the clubs and ultimately 'protect the long-term viability and sustainability of European club football'. It is clear that many, if not most European football clubs have financial problems. According to the most recent survey of European football club finances by UEFA (Union of European Football Associations (UEFA), 2012a), 63\% of top division clubs in Europe reported an operating loss, $55 \%$ reported a net loss, 38\% reported negative net equity and auditors raised 'going concern' doubts in $16 \%$ of cases. While it seems clear that UEFA views these figures with concern, their powers are limited. While there are around 700 top division clubs in Europe, and many thousands that operate below this level, only 235 play in UEFA competitions and are therefore directly affected by FFP rules. Moreover, the FFP rules exempt clubs with revenues or expenses below $€ 5$ million, which constitutes roughly half of all top division clubs and $41 \%$ of all clubs qualifying for UEFA competition (only 77 European clubs have revenues in excess of $€ 50$ million). 
There is also no doubt that there is a long history of financial instability in European football. As long ago as 1968 a British government report found that there existed a number of clubs that were 'living in near permanent poverty' and posed the following questions:

If these clubs continue to incur losses at the present rate or at an increased rate, one must ask who will take responsibility for the accumulated deficits in, say, a decade's time, or even less? Is it possible for them to remain in existence or will there be increasing insolvency? (Chester, 1968, p. 45)

Examples of financial failure going back more than 20 years are not hard to find:

- England - between 1982 and 1986 there were ten cases where clubs underwent court procedures relating to insolvency, twice in the case of Wolverhampton Wanderers (Szymanski, 2012).

- France - St Etienne (1982), Bordeaux (1990-91), and Marseille (1993) - see Gouguet and Primault (2006, p. 49).

- Spain - during the 1980s Spanish clubs owed large sums to the tax authorities that they were unable to pay, leading to a government mandated restructuring in 1990 following the Ley del Deporte (Ascari and Gagnepain, 2006, p. 78).

- Italy - 'bankruptcies have been common in the lower leagues since the 1970s ... In $1993 \ldots$ six teams were excluded from Serie C1 alone due to financial irregularities' (Foot, 2007, p. 541).

Despite this financial instability, clubs almost always survive. For example, of the 74 clubs playing in the top divisions of England, France, Italy and Spain in 1949/50, $46(62 \%)$ were competing in their top division in 2012/13, 13 were playing in the second tier. Of the remaining 15, all but three were still competing in professional leagues. The three remaining cases are all French; Stade Français de Paris returned to amateur status and still competes, while FG Nancy was disbanded in 1965 and Roubaix Tourcoing in 1970. Although many of these clubs have experienced insolvency crises, several of them on more than one occasion, one would be hard put to find any other commercial activity which displayed such stability. Given this history the recent concern of UEFA with financial stability seems puzzling. Furthermore, bankruptcies are primarily a problem among teams in the lower tiers of European football, which would not be affected by Financial Fair Play.

3.2.2. Regulating sugar daddies. A second explanation has to do with the so-called 'sugar daddies'. ${ }^{10}$ Many fans complain that it is unfair that wealthy owners are able to 'buy' a championship simply by using their financial muscle (as for example, appeared to be the case with Manchester City in the 2011/12 season). Some have labelled the practice 'financial doping', by analogy to doping by athletes who use banned sub-

${ }^{10}$ There are a number of high profile sugar daddies who attract particular disapproval, e.g. Roman Abramovitch (who owns Chelsea) and Sheikh Mansour (who owns Manchester City). 
stances to enhance their performance. ${ }^{11}$ Given that UEFA's President, Michel Platini, has referred to this on several occasions and given that the rules contain the phrase 'fair play', this might well be seen as the motivation. The regulations, however, go far beyond the handful of clubs that have received large injections of cash. Chelsea and Manchester City, for example, do not have any problems with overdue payables. Undoubtedly there is an ethical dimension to the activities of governing bodies, but the regulations seem to dwell more on financial efficiency than fairness per se. Moreover the lines being drawn seem hazy. Thus, for example, Chelsea receives large cash injections from a Russian oligarch, whose financial support will be restricted by FFP, while the Bundesliga team Schalke 04 has received hundreds of millions of euros in sponsorship from Gazprom, the Russian gas producer which is controlled by businessmen close to the Russian government, and will not be prevented from receiving further financial support from this source.

3.2.3. Regulating competitive balance. Following the logic of the American model, one might think that competitive balance could be a rationale for FFP, and the issue has certainly generated growing concern over recent years. European football has always been characterized by competitive imbalance. For example, if we compare the period 1971-91 with the period 1992-2012, then in the five largest European top divisions (England, France, Germany, Italy and Spain) the number of league titles won by the three most successful clubs has risen to $77 \%$, but only from $71 \%$. Most leagues are, and always have been, dominated by no more than three or four teams, and some by one or two.

The perception of imbalance partly stems from the expansion of the UEFA Champions League. This competition involved only the league champions of each country until 1997/98. Since then associations with better success records are allowed to enter more teams, up to a maximum of four. Not surprisingly these clubs tend to come from the larger countries, especially England, Germany, Italy and Spain. These countries produced 26 of the winners of the competition out of the first $40(65 \%)$ but since 1996 they have supplied all but one of the winners (94\%).

Another important point with regard to competitive balance is the distribution of Champions League prize money. As depicted in Figure 1, the total pay-outs to participating teams have steadily risen from $€ 100$ million in 1996 to around $€ 1$ billion in 2013. UEFA employs a sharing rule which allocates around $45 \%$ of the total prize money to teams in relation to the size of their home country's national TV market (the so-called 'market pool'), around $30 \%$ is paid as a fixed prize for participation in the tournament and the remaining $25 \%$ is granted based on performance in the tournament. Figure 1 clearly shows that this has led teams from large countries (with large TV markets and strong performances on the pitch) to earn by far the largest share of

11 See, for example, Müller et al. (2012). 


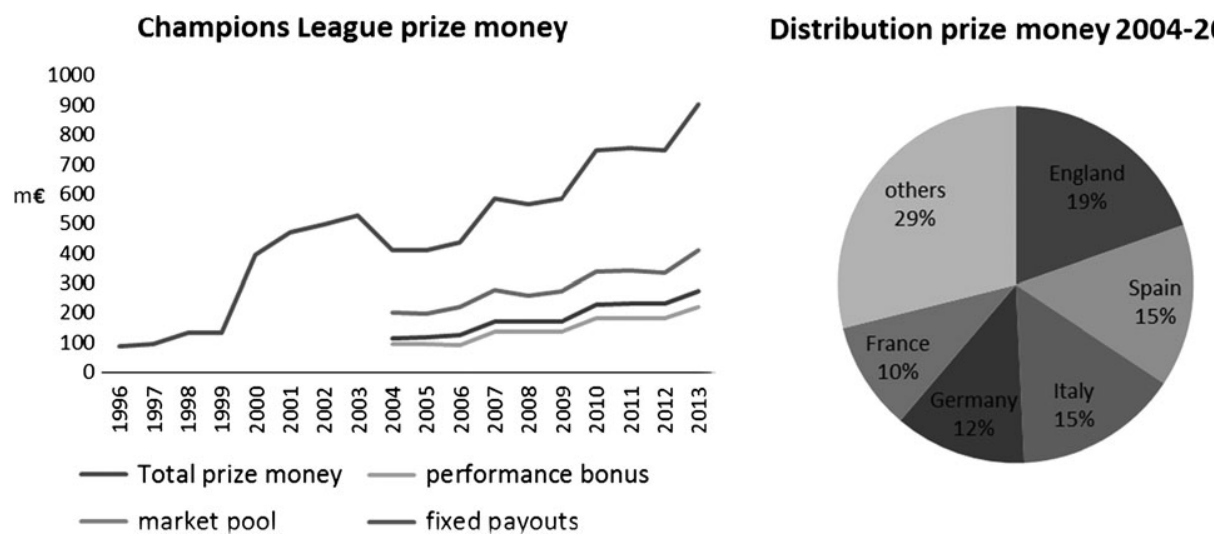

Figure 1. Ghampions League prize money distribution

the Champions League pay-outs. Teams from the big 5 leagues - England, Spain, Germany, Italy and France - have collectively taken home 71\% of all proceeds from the Champions League over the past 10 years.

This prize money policy is hard to reconcile with a stated desire to improve competitive balance for two reasons. First, explicitly favouring teams from the dominant leagues through the market pool can only cause the gap in spending power between the big and small leagues, which is considerable already, to widen even further. Second, this policy implies that within each national league a couple of top (mostly large market) teams receive a considerable boost in revenues, which further enlarges the rift in financial power at the national level. These observations may explain why UEFA has avoided claiming competitive balance as a rationale for FFP. On top of this, UEFA may realize that FFP is in fact a poor tool to improve competitive balance, as we show below.

3.2.4. Regulating wage spending. Our argument is that the break-even rule operates analogously to a salary cap. As mentioned above, the key benefit that is claimed for a salary cap in North America is that it promotes competitive balance amongst the teams in the league (see, for example, Fort and Quirk, 1995; Vrooman, 1995; Késenne, 2000; and Dietl et al., 2009; although Vrooman argues that the main purpose of the cap is to hold down salaries while teams evade the effects of the cap by working around the constraint). Clearly, since FFP only limits spending of an individual club in proportion to its own resources, and these resources vary hugely in European football, no such benefit can be claimed. Indeed, some have argued that the break-even rule will reduce competitive balance by limiting the opportunity of smaller teams to erode the dominance of the established teams since they will not be able to use outside resources to fund a challenge.

Our analysis shows how the impact of the restraint goes beyond those clubs wanting to spend more than their football resources. Given that higher spending tends to gen- 
erate better sporting performance, restraining the spending of some clubs reduces the cost of winning for all clubs. Thus there will be spill-over effects to clubs not directly affected by the limit, by lowering the cost of achieving a given level of success. The simulation results from our empirical model show that the effect on total payroll spending is substantial. Once fully operational, the FFP rules could reduce the ratio of payroll spending to turnover in the larger football nations by up to $15 \%$. Thus we argue that the vertical restraint introduced by UEFA will produce an anti-competitive outcome which is comparable to the horizontal salary cap agreements which exist in the US, without the latter's pro-competitive balance effects. ${ }^{12}$

Why would UEFA wish to impose this restraint on teams entering their competitions? UEFA may believe that such restraints will enhance the value of the competitions they run and the strength of the regulatory body itself. UEFA generates an annual income of around $€ 1.5$ billion, of which more than two-thirds is derived from the Champions League. As discussed above, however, most of that money is being disbursed to clubs and national associations. If clubs are able to spend less on player salaries it may also be possible for UEFA to retain a larger share of its income which it can then devote to projects it wishes to advance.

\section{EMPIRICAL EVIDENCE}

In this section we develop and estimate a stylized model of football league competition to examine the effect of the break-even rule in a set of European football leagues.

\subsection{A stylized model of league competition under Financial Fair Play}

A typical European football league consists of $n$ clubs divided into $k$ hierarchical divisions (or tiers), where mobility between divisions is permitted by the system of promotion and relegation. ${ }^{13}$ Each division $d$ in season $t$ contains $n_{d t}$ teams that play each other twice each season, once at home and once away, generating $2 *\left(n_{d t}-1\right)$ contests for each club.

We assume that in each contest between teams $i$ and $j$ the probability of winning, drawing or losing the game is driven by three variables. First, when teams invest more

\footnotetext{
12 This result has already been discussed in a theoretical context by Dietl et al. (2009) who examine the effect of a salary cap based on a fixed percentage of team income, exactly the kind of cap imposed by the FFP break-even rule. Their model shows that while implying more variation in spending than an American style cap, it unequivocally reduces aggregate salaries. Our analysis provides an empirical estimate of the size of this effect. Two papers have looked at the welfare effects of FFP in theoretical models (Madden, forthcoming; Franck and Lang, 2012), but found opposite results.

13 Under this system teams finishing at the bottom of the league table are forced to play in a lower division in the following season (relegation), whereas teams finishing at the top of the table gain the right to play in a higher division (promotion). In other words, sporting merit determines which teams play in the higher tiers, as opposed to the league choosing which cities may host teams, as is common in the American major leagues. See previous sections for more on this issue.
} 
in playing resources then, all else equal, their chances of winning should increase. We proxy investments in talented players by the teams' total payrolls, which we denote by $p_{i t}$ and $p_{j t}$ for $i$ and $j$ respectively. Previous research has shown that payrolls in football are highly correlated with team success over the season (see e.g. Szymanski and Smith, 1997; Forrest and Simmons, 2002). Playing talent is highly mobile and the typical means of attracting a player is to offer a significant increase on their current wage. Since individual performance is directly observable, we expect a player's wage to be an accurate reflection of his talent level. In line with the sports economics literature, we assume that relative differences, rather than absolute differences in payroll drive the result of the contest. Second, teams need not be equally productive in transforming their playing talent into performance on the field. One might think of team spirit, the quality of the medical support team, the training facilities or the scouting operation as explanatory factors for such differences. We introduce a team specific term, $\omega_{i t}$ and $\omega_{j t}$, to denote the teams' productivities in the contest. An important thing to note is that because of the relative nature of the contest, these productivities should only be interpreted in comparison to other teams in the contest and not in an absolute sense. Finally, the presence of home advantage results in ceteris paribus higher probabilities of success for the home team. This may stem from a number of factors such as the bias of the fans toward the home team, the convenience for the players (e.g. less travel) or the bias of the referees (see e.g. Garicano et al., 2005). To capture these effects we propose the following expression to model $y_{i j t}$, which is the outcome of a contest between home team $i$ and away team $j$ in season $t$ :

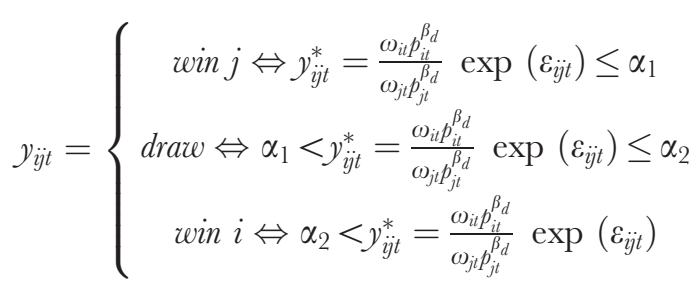

In Equation (1) we need to map a function of continuous variables, such as the wage, into the outcome of the contest, which has only three possible values, that is, home win, draw or home loss. So we introduce an unobservable, continuous variable, $y_{i j t}^{*}$, which drives the result of the contest. When $y_{i j t}^{*}$ reaches a certain threshold $\alpha_{2}$, the home team wins. When it falls below the threshold $\alpha_{1}$, the away team wins. When it lies in between both thresholds the contest ends in a draw. To get the intuition for the expression of $y_{i j t}^{*}$, observe that we start from the relative investments in payrolls, $p_{i t}$, and $p_{j}$, of the home team $i$ versus the away team $j$ and take it to the power $\beta_{d}$. We refer to $\beta_{d}$ as the division specific return parameter, which measures the sensitivity of the contest to investments in payroll. For each team we then multiply this by the team specific productivities, $\omega_{i t}$, and $\omega_{j t}$, in the contest. We also add an exponential noise term $\varepsilon_{i j t}$ to allow for chance factors which are specific to each game. These are evidently inherent in any sports contest, as one of the main attractions in sports is 
precisely that the best team does not always win. Our specification does not allow to estimate a separate home advantage effect, as this is taken up by the threshold terms $\alpha_{1}$ and $\alpha_{2}$.

In European football leagues, teams obtain 3 points for a win and 1 point for a draw in any given game. Points are aggregated over all games to obtain the end-ofseason ranking. This final ranking then determines which teams win the title, are promoted to higher tiers, qualify to play in the European-wide competitions or are relegated to a lower tier. ${ }^{14}$ This renders the relative number of points won over the season (denoted $w_{i t}$ ) an important driver of a football club's revenues. Clubs typically obtain revenues ( $r_{i t}$ in our notation) out of four main sources, match-day income from ticket sales and catering at the stadium, commercial income from sponsorship deals, media rights sales and prize money from European competitions. Points are a crucial driver for each of these sources. First, the ranking is in itself an important driver of fan interest, which translates into higher match-day and merchandise receipts. Second, in most European leagues the sharing rule for collectively sold media rights contains a percentage which is shared based on league performance. ${ }^{15}$ Finally, the European competitions, especially the Champions League, guarantee teams a significant amount of prize money if they qualify by ending near the top of the ranking. A second factor which impacts team revenues is the quality and capacity of the team's stadium. As clubs usually have no large tangible assets apart from their stadium annex training facilities, we proxy the stadium value by the book value of their tangible fixed assets, $k_{i t}$. Further, the size of the team's local market and the division and country a team plays in, also have a large effect on the revenue potential of the team. We use team and year-division specific dummies, $\gamma_{i}$ and $\gamma_{d t}$, to control for these effects. We finally assume the revenue function to be observed with a random error term $v_{i t}$. Revenues are therefore modelled by this Cobb-Douglas style function:

$\log \left(r_{i t}\right)=\beta_{w} \log \left(w_{i t}\right)+\beta_{k} \log \left(k_{i t}\right)+\gamma_{i}+\gamma_{d t}+v_{i t}$

Team profits, $\pi_{i t}$, are simply given as the difference between revenues and the sum of payroll and non-payroll costs, $c_{i t}$. We get that $\pi_{i t}=r_{i t}\left(w_{i t}\left(p_{i t}, p_{-i t}\right)\right)-p_{i t}-c_{i t}$.

We assume club owners have a positive valuation for success on the field and for earning money on their investment in the team. Each owner therefore has an individual utility function of the form, $U_{i t}\left(\pi_{i t}^{+}, w_{i t}^{+}\right)$, which is increasing in both profits and relative points won. Before the start of the season, the owner maximizes his utility by choosing a budget constraint $b_{i t}=r_{i t}\left(w_{i t}\left(p_{i t}, p_{-i t}\right)-p_{i t}-c_{i t}\right.$, which indicates the level of profits/losses he wants to make. Depending on his individual taste for points versus monetary pay-offs, the owner may set a positive amount he wants to earn as a return

14 There are usually no playoffs, except to decide on promotion to higher leagues.

${ }^{15}$ Currently English teams share 25\% of national TV rights money based on performance, French and Italian teams each share $30 \%$ based on performance. Spain does not have collective sales of TV rights at this time. 
on his investment or a negative amount he is willing to put into the team to finance its losses and promote its results on the field-of-play. This simple specification captures both owners who approach a football club as a regular business activity and the socalled sugar daddy owners. Given the budget constraint, the manager of the team maximizes its sports performance. Since we assume investments positively affect performance, this is achieved by investing up to the point where the owner's constraint is binding. We further assume the manager minimizes non-payroll costs in his efforts to drive up wage spending. The manager therefore sets a payroll equal to $p_{i t}^{*}$, which solves the budget constraint equation $b_{i t}=r_{i t}\left(w_{i t}\left(p_{i t}^{*}, p_{j t}^{*}\right)\right)-p_{i t}^{*}-c_{i t}$. A Nash-equilibrium arises when all owners choose a budget constraint, which maximizes their utility given the budget constraints chosen by all other owners. We refer interested readers to the Appendix, section A1, for details on how we have calculated the equilibrium and checked for uniqueness.

The introduction of the FFP break-even constraint in this stylized model implies that the regulator puts a lower bound, $b_{i t}^{F F P}$ on negative budget constraints. In other words, certain owners who are willing to finance large financial losses to make their team competitive are no longer allowed to do so. In turn, the managers of teams affected by the break-even constraint have to cut back on payrolls, because they have already minimized other costs. The direct effect of the break-even requirement is therefore a decline in payrolls for affected teams. Since payrolls across the league are lower, the logic of our model implies that all teams win more points for a given payroll and consequently increase their revenues. Even a club whose budget is constrained by the break-even rule will benefit from this effect, as long as it is not the only constrained club in the league.

The reaction of the owners to the introduction of the break-even rule depends on their individual taste for on-field success versus financial returns, or in terms of our model on $U_{i t}\left(\pi_{i t}^{+}, w_{i t}^{+}\right)$. As discussed above, individual tastes differ quite substantially across owners in most leagues and unfortunately it is infeasible to infer the utility function for each individual empirically. We will therefore simulate the effect of the breakeven rule under two hypotheses regarding the owners' reactions. If an owner is 'profit' oriented, we assume he puts more weight on financial gains. Under this hypothesis an unconstrained owner, who gets a windfall revenue increase, does not reinvest any of these gains into the playing squad, but instead pockets the extra money. A constrained 'profit' oriented owner reinvests these extra revenues if team payroll is below its original level, but pockets any windfall revenue, which would put him above that point. If on the other hand an owner is 'win' oriented, we assume he is more interested in the on-field performance of his team. He consequently invests any extra revenues to increase the value of his playing staff.

Since we have no way to empirically establish which owners are 'win' or 'profit' oriented, we report two extreme scenarios in the simulation result tables. Under the 'profit' scenario all owners behave 'profit' oriented. This implies that if $b_{i t}^{F F P}>b_{i t}$ for at least one club, then (a) payrolls fall for at least one constrained club, (b) payrolls for 
other affected clubs cannot increase and (c) payroll is not affected for all unconstrained clubs. Under the 'win' scenario we assume all owners are 'win' oriented. In this scenario all unconstrained teams end up with higher payrolls, while the constrained clubs may see either a decline or an increase in their wage bills, that is, if $b_{i t}^{F F P}>b_{i t}$ for at least one club, then (a) payroll falls for at least one constrained club, (b) all other constrained clubs may see an increase or decline in payrolls and (c) payroll rises at all unconstrained clubs.

Any real-life league is unlikely to fit exactly in either of these two scenarios, because (a) any real-life owner would probably reinvest a share of his extra revenues and pocket the remainder and (b) football leagues typically have heterogeneous owners, where some are better described by the 'profit'-scenario while others fit the 'win'scenario better. However, we show in Appendix section A3 that any simulation with a mixture of both types of owners leads to average league payrolls and wage-to-turnover ratios, which are in between those found in these two extreme scenarios. Calculating the effects under these two scenarios is therefore instructive, as they describe an interval in terms of the rent shifting outcomes on which the outcome of any real-life league would fall.

\subsection{Data}

In order to perform our empirical analysis we have gathered data on four major European football leagues, that is, the English, Spanish, Italian and French league. This dataset allows us to provide a relatively complete assessment of the impact of the break-even rule for three reasons. First, our dataset covers four of the 'big five' European football leagues, whose clubs dominate the professional football industry in Europe on the playing field and in economic terms. For example, since the start of the Champions League in 1993, clubs from the big five leagues have won all but two Champions League titles and only three teams from other leagues have ever qualified for the final. These are also the only football leagues whose average club revenues exceeded $€ 50$ million in 2010 (see UEFA, 2012a). Second, although we were unable to obtain data on all of the clubs in the German Bundesliga, we expect that the effects of the break-even rule would be fairly limited in Germany. The FFP rules are similar to the German club licensing system, so clubs already operate under a comparable set of restraints. Third, the likely impact of the break-even constraint in leagues operating in smaller European football markets is limited by the 'acceptable deviation', which defines an upper bound on the difference between football related costs and revenues UEFA tolerates under FFP. Initially, an average loss of $€ 15$ million per season would be accepted, gradually declining over time to $€ 5$ million over three seasons. Given the low turnover of clubs outside the big five leagues, most clubs in smaller countries would not be financially capable of incurring large enough losses as a percentage of turnover to violate the acceptable deviation. In other words, FFP is not a binding constraint for most clubs outside of the big five leagues. 
Table 1 gives an overview of selected summary statistics at the game level for each league in our dataset. The data first consists of a set of sports related variables, such as the result of each game, the tenure of the manager expressed in games and the number of points obtained over the season. On top of that we use a couple of financial variables, the total wage bill and revenues over the season and the book value of tangible fixed assets. For England, the data cover the 2000-2010 seasons of the top two divisions in the English Football Association, currently known as the Premier League and Championship. We retrieved all financial information from the original club accounts, which we acquired from Companies House. ${ }^{16}$ We have complete information for around $86.5 \%$ of all games played in our sample period with the large bulk of the missing games in the second division. For Spain, we obtained accounting data on the 1998-2011 seasons, but only for the first division (also known as the Primera Division or La Liga). Our financial data cover about $91.3 \%$ of all games played in the Primera Division over this period. For Italy, we got hold of a database containing the accounts of the first and second division clubs (Serie A and B) over the 2002-2011 seasons. Approximately $70.3 \%$ of all Serie A and Serie B games have full financial information for both teams. Finally, for France we use data provided by the Direction Nationale du Contrôle de Gestion (DNCG), ${ }^{17}$ which includes a summary of the balance sheet and the profit and loss account for each team in the top two divisions. Our coverage reaches around $77.2 \%$ of all games played over the 2004-2011 seasons.

Looking at the summary statistics in Table 1 readily reveals a couple of preliminary facts about the leagues in our dataset. First, it appears that home advantage is an important factor across Europe, with the home teams winning more than $45 \%$ of games in all leagues, whereas between $25 \%$ and $30 \%$ of games end in a draw. Second, English managers appear to have considerably longer tenures than managers in other leagues. This could be due to cultural differences in the approach to firing managers, but it is also driven by a couple of long-standing managers, such as Alex Ferguson at Manchester United and Arsène Wenger at Arsenal. Third, the English teams have been financially dominant over our sample period, in terms of both average revenue and average wage bill. This is mainly due to the fact that small market English clubs generate significantly larger revenues than their continental counterparts. Only the top teams in Italy, Spain and France are capable of keeping up with the English teams in financial terms. Another noteworthy observation is that on average teams ran deficits in all countries, with average losses ranging from $€ 300,000$ in France up to around $€ 7$ million in England and Italy. A final observation is the difference in the level of tangible fixed assets between England and Spain on the one hand and Italy and

\footnotetext{
${ }^{16}$ In accordance with the FFP rules we convert these amounts to UK pounds using the average ECB exchange rate over the reporting period, retrieved from:http://sdw.ecb.europa.eu/browseTable.do? node $=2018794 \&$ CURRENCY $=$ GBP $\&$ sfl $1=4 \& D A T A S E T=0 \& s f l 3=4 \& S E R I E S \_K E Y=120 . E X R . D$.

GBP.EUR.SP00.A

17 See http://www.lfp.fr/corporate/dncg for more information.
} 


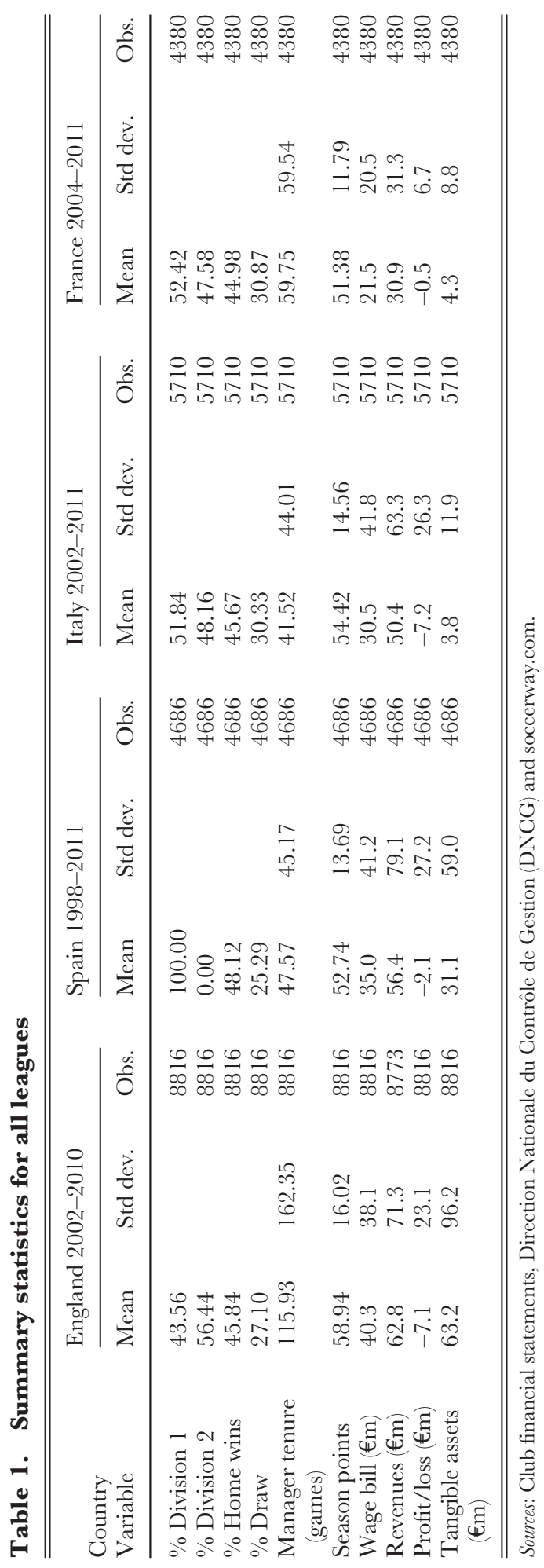


France on the other hand. To some extent this reflects whether clubs own their stadium, as in Italy and France more clubs play in publicly funded stadiums.

\subsection{Estimation procedure and results}

We now use our dataset to estimate the simple model we constructed to simulate the introduction of the break-even rule. ${ }^{18}$ We therefore need to identify all the elements in the model which impact the equilibrium budget constraints. As discussed above, we cannot credibly infer the individual utility functions of the owners, $U_{i t}\left(\pi_{i t}^{+}, w_{i t}^{+}\right)$. Fortunately, we can observe the budget constraints under the laissez-faire equilibrium directly from the accounts, if we assume these are equal to the realized profits or losses. The accounts also contain the laissez-faire equilibrium talent investment, $p_{i t}^{*}$ which are given by the total payroll inclusive social security contributions and taxes, and non-payroll costs, $c_{i t}$, which are simply the total costs from the profit and loss account minus payroll costs.

A first relationship we need to estimate is the contest function (1). This exercise presents a challenge in that we cannot directly observe the productivity of the clubs in our dataset. Yet, club owners and managers can observe how productively each club operates, which implies that they will condition their choices on the productivity levels of all teams in the league. We expect, for example, that managers of productive teams select higher payrolls, as they know these will pay off in terms of on-field success and revenues. If we neglect to control for productivity we might attribute the success of these teams entirely to their higher payrolls instead of the productivity advantage they enjoy. This could lead us to overestimate the returnon-investment parameters in Equation (1). We employ two distinct approaches to get around this problem. In a first approach we replace $\omega_{i t}$ by a club-specific constant, a so-called fixed effects (FE). This implies that we assume productivity differs between teams, but remains constant over time, at least in the period covered by our dataset. A second approach, which has been introduced by Olley and Pakes (1996) to estimate production functions, is to infer productivity levels using an instrumental variable. A good instrument should correlate strongly with productivity, such that we may gain a lot of information about productivity levels. At the same time, however, it should not affect winning directly, because in that case it should have been in the original contest function specification. We use the tenure of the current manager and the level of tangible fixed assets as productivity proxies. We argue that manager tenure is positively related to productivity on the field, because it is common practice to fire the coach if the team appears to be unproductive. The level of tangible fixed assets is positively correlated to productivity, because productive teams hold larger capital stocks, in the form of training facilities and stadia. Since the fixed

${ }^{18}$ For more details on the estimation procedure see the Appendix, section A2. 
effects approach does not require finding a suitable instrument, this approach is more robust and more widely applicable. On the other hand, the inflexibility of assuming time-invariant productivity may lead us to underestimate the return parameters, as has been illustrated in the production function context by Olley and Pakes (1996). On top of that the fixed effects approach also requires estimating more parameters, which reduces the precision of our estimates.

Table 2 presents the contest function results using no productivity controls (NG), fixed effects $(\mathrm{FE})$ and productivity instruments $(\mathrm{O}-\mathrm{P})$. On the whole, wage spending has a significant positive effect on game results in all countries. We find the highest estimates for the return parameters in the NG columns and the lowest for the FE procedure, with the O-P approach in between the two, which is exactly what we would expect based on previous results from the production function literature. The FE estimates display the largest standard errors, which leads to a couple of insignificant estimates of the return parameters. The estimates for different divisions vary significantly, with the English first division clearly showing the highest sensitivity of results to spending. As a general rule, the return coefficients for the first tier appear to be higher than those for the second tiers. Table 2 further presents a couple of goodness-of-fit statistics for each model. The Wald-test statistics show that all parameters in our model, including those not reported, are jointly significant. The pseudo $r$-squared, AIC and log likelihood indicate that in general the FE approach generates the best fit for our dataset.

To enhance the readability of Table 2, we do not report all parameters used to measure the teams' productivities. Instead Table 3 shows summary statistics on the productivity results from the FE and O-P approaches. Since these productivities are only meaningful in relation to the other teams in the league, we rescale them by dividing by the country average. The expected overall average productivity is therefore equal to 1 , which is confirmed by Table 3 . The productivity of teams at the top level is on average higher in all countries, which is intuitive as the promotion and relegation system favours the presence of more productive teams in the top league. ${ }^{19}$ The first divisions in England, Spain and Italy also boost higher maximum productivities due to a couple of top teams, which have been able to build a sustained productivity advantage. ${ }^{20}$ Table 3 also depicts the correlation coefficient between payroll and productivity, which helps to explain our estimation results for the contest function. If these correlations are large, as is the case for England, the high spending teams are on average more productive on the pitch. In this case we should see that using the FE and O-P approaches leads to sharp declines in the estimate of the return parameter. If on the other hand productivity and payroll are not connected, as for example in France, the big spenders are not more productive in producing wins. We should then

19 The high maximum productivity in Italy's second division is due to Juventus, a traditional top team, which was relegated due to the Calciopoli bribing scandal.

${ }^{20}$ Typical examples are Arsenal, Manchester United and Liverpool in England, Barcelona and Real Madrid in Spain and the Milan teams in Italy. 


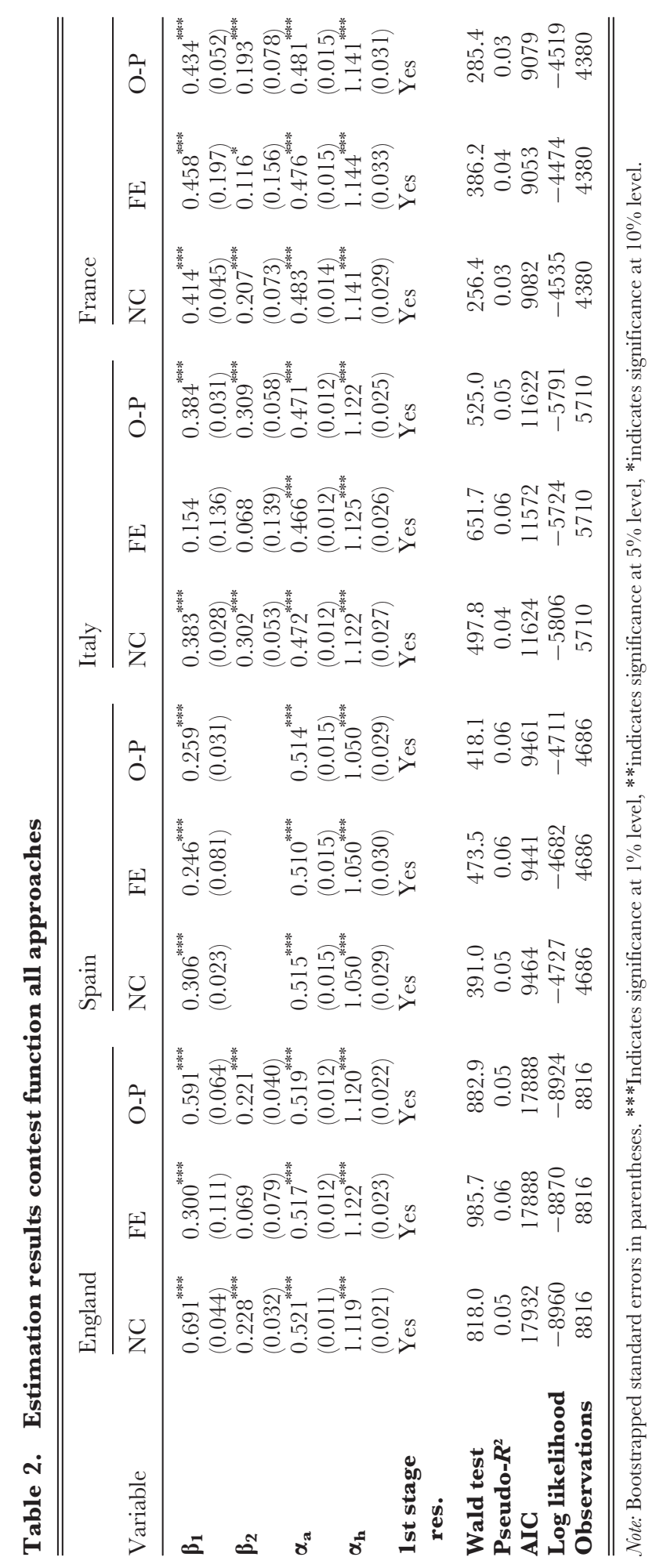


Table 3. Productivity estimates

\begin{tabular}{|c|c|c|c|c|c|c|c|c|}
\hline \multirow[b]{2}{*}{ Relative productivity } & \multicolumn{2}{|c|}{ England } & \multicolumn{2}{|l|}{ Spain } & \multicolumn{2}{|l|}{ Italy } & \multicolumn{2}{|c|}{ France } \\
\hline & $\mathrm{FE}$ & $\mathrm{O}-\mathrm{P}$ & $\mathrm{FE}$ & O-P & $\mathrm{FE}$ & $\mathrm{O}-\mathrm{P}$ & $\mathrm{FE}$ & $\mathrm{O}-\mathrm{P}$ \\
\hline \multicolumn{9}{|l|}{ All } \\
\hline Mean & 1.010 & 1.002 & 1.001 & 0.999 & 0.992 & 1.001 & 0.995 & 0.999 \\
\hline Std dev. & 0.286 & 0.107 & 0.122 & 0.084 & 0.278 & 0.056 & 0.151 & 0.056 \\
\hline Minimum & 0.467 & 0.867 & 0.556 & 0.884 & 0.385 & 0.736 & 0.534 & 0.719 \\
\hline Maximum & 1.909 & 1.395 & 1.230 & 1.314 & 1.715 & 1.118 & 1.272 & 1.094 \\
\hline Correlation payroll & 0.565 & 0.337 & 0.461 & 0.525 & 0.874 & -0.080 & 0.081 & -0.068 \\
\hline Correlation FE-OP & \multicolumn{2}{|c|}{0.716} & \multicolumn{2}{|c|}{0.355} & \multicolumn{2}{|c|}{-0.071} & \multicolumn{2}{|c|}{0.492} \\
\hline \multicolumn{9}{|l|}{ 1st division } \\
\hline Mean & 1.145 & 1.033 & & & 1.121 & 0.999 & 1.042 & 1.011 \\
\hline Std dev. & 0.299 & 0.124 & & & 0.257 & 0.059 & 0.145 & 0.056 \\
\hline Minimum & 0.700 & 0.876 & & & 0.550 & 0.736 & 0.775 & 0.719 \\
\hline Maximum & 1.909 & 1.395 & & & 1.715 & 1.116 & 1.272 & 1.094 \\
\hline \multicolumn{9}{|l|}{ 2nd division } \\
\hline Mean & 0.833 & 0.959 & & & 0.785 & 1.006 & 0.913 & 0.978 \\
\hline Std dev. & 0.131 & 0.051 & & & 0.160 & 0.053 & 0.124 & 0.049 \\
\hline Minimum & 0.467 & 0.867 & & & 0.385 & 0.779 & 0.534 & 0.797 \\
\hline Maximum & 1.099 & 1.130 & & & 1.562 & 1.118 & 1.231 & 1.082 \\
\hline
\end{tabular}

expect no movement in the estimation results, which is confirmed by the results in Table 2. Table 3 finally compares the different estimates of team productivity again using the correlation coefficient. These numbers show that in England, Spain and France the FE and O-P estimates point in the same direction, which is reassuring for the robustness of our results. In Italy, however, the difference between both methodologies seems quite large, as the correlation coefficient is negative. Finally Table 3 shows that using fixed effects leads to more extreme spreads in estimated productivities in all leagues.

A second relationship we need to identify is the revenue function in Equation (2). Table 4 reports our estimates separately for all leagues. Given the Cobb-Douglas

Table 4. Revenue function estimation

\begin{tabular}{lllll}
\hline \hline Variable & England & Spain & Italy & France \\
\hline Rel. points & $0.259^{* * *}$ & $0.427^{* * *}$ & $0.428^{* * *}$ & $0.386^{*}$ \\
Fixed assets & $(0.048)^{* *}$ & $(0.084)$ & $(0.088)$ & $(0.055)$ \\
& $0.095^{* * *}$ & -0.003 & 0.011 & $0.051^{*}$ \\
Promoted & $(0.016)$ & $(0.018)$ & $(0.018)$ & $(0.018)$ \\
& 0.024 & $-0.222^{* * *}$ & $-0.109^{* *}$ & -0.045 \\
Relegated & $(0.029)$ & $(0.052)$ & $(0.046)$ & $(0.038)$ \\
& $0.411^{* * *}$ & & $0.277^{*}$ & $0.142^{* * *}$ \\
Firm fixed effects & $(0.039)$ & & $(0.070)$ & $(0.038)$ \\
Division- year effects & Yes & Yes & Yes & Yes \\
R-squared & Yes & Yes & Yes & Yes \\
Observations & 0.848 & 0.640 & 0.675 & 0.843 \\
\hline \hline
\end{tabular}

Note: Standard errors in parentheses. ***Indicates significance at $1 \%$ level, **indicates significance at $5 \%$ level, *indicates significance at $10 \%$ level. 
Table 5. Summary statistics end-of-season points of the 'no FFP'- scenario for all estimation approaches

\begin{tabular}{rllrrrr}
\hline \hline \multirow{5}{*}{ England } & Real & Null & $\begin{array}{c}\text { No } \\
\text { controls }\end{array}$ & $\begin{array}{c}\text { Fixed } \\
\text { effects }\end{array}$ & Polynomial \\
& Average & 53.47 & 51.91 & 52.18 & 52.34 & 52.37 \\
& Std dev. & 17.70 & 7.89 & 16.53 & 16.34 & 17.21 \\
& RMSE & - & 19.89 & 8.13 & 5.93 & 7.44 \\
\multirow{5}{*}{ Spain } & AAE & - & 16.56 & 6.76 & 4.52 & 5.74 \\
& Average & 53.05 & 52.42 & 52.21 & 52.23 & 52.24 \\
& Std dev. & 16.77 & 7.98 & 10.60 & 11.97 & 11.32 \\
& RMSE & - & 18.08 & 7.93 & 7.83 & 6.77 \\
\multirow{5}{*}{ Italy } & AAE & - & 13.55 & 5.68 & 6.20 & 5.24 \\
& Average & 53.63 & 51.46 & 51.50 & 51.30 & 51.38 \\
& Std dev. & 13.70 & 7.77 & 12.04 & 12.63 & 11.58 \\
& RMSE & - & 15.18 & 9.01 & 8.36 & 8.20 \\
& AAE & - & 12.20 & 7.13 & 6.62 & 6.31 \\
& Average & 50.50 & 50.95 & 51.27 & 51.33 & 51.23 \\
& Std dev. & 11.75 & 7.65 & 10.00 & 12.08 & 10.12 \\
& RMSE & - & 13.57 & 7.95 & 5.56 & 6.50 \\
& AAE & - & 10.39 & 6.31 & 4.23 & 5.46 \\
\hline \hline
\end{tabular}

Note: RMSE=random mean square error of the simulated end-of-season points; $\mathrm{AAE}=$ average absolute error of the simulated end-of-season points.

specification we assumed, these parameters should be interpreted as elasticities. For example, in England a 1\% increase in the relative number of points, leads to a $0.26 \%$ increase in revenues. The relative number of points obtained is a highly significant driver of revenues in all leagues. We find the smallest elasticity in England, with significantly larger estimates for France, Spain and Italy. This difference could be due to the relative importance of different revenue sources, which may be more or less sensitive to winning, or to different sales mechanism for media rights, which could be more or less favourable to the better performing teams. The level of tangible assets has a significant impact on revenues in France and England. The insignificance of this variable for Spain and Italy could be explained by the fact that some teams do not own their stadium, in which case its value does not show up in the accounts. Alternatively, this might reflect a lack of variation in the level of assets over our sample period, which makes it difficult to identify the coefficient separately from the constant effect of the team. As expected, freshly promoted and relegated clubs enjoy ceteris paribus lower and higher revenues respectively. In terms of the fit of this revenue model, the $r$-squared indicates that the model performs better for England and France than for Spain and Italy.

Table 5 investigates the explanatory power of our model in terms of sports results by comparing the actual points table in the simulated seasons to a null-model ${ }^{21}$ and

21 The null model takes the relative frequencies of a loss, draw and win as the only predictors for the probability of the game results. We simulate 1,000 runs of the competition using random draws from this probability distribution and report the averages over these runs in terms of average points, standard deviation and prediction error. 
the results of the estimation approaches outlined above. In most cases, the models find similar averages, which fit closely to the observed values. In terms of the standard deviation the null model may be regarded as a lower bound for each league. Most estimated models are much more precise in predicting the standard deviation, however. The only major exception is the Spanish league where all models underestimate the standard deviation, because they fail to correctly predict the exceptionally strong season of Barcelona and Real Madrid. Table 5 shows two goodness-of-fit measures, the root mean squared error and the mean absolute error, ${ }^{22}$ which decreases if the model fit improves. Over all leagues, the estimated models show a considerably better fit than the null-model, which again shows the importance of payrolls in explaining football results. Unsurprisingly, the NC-model performs worst among the estimated models, clearly an effect of failing to control for productivity differences between teams. The O-P model performs better than the FE model for Spain and Italy, while the reverse is true for England and France. We therefore present simulation results for both approaches.

\subsection{Simulation results}

We have now identified all the necessary elements to simulate the introduction of the break-even constraint. In our simulation we look at five different cases, each time using the last available season for the top division in each country. First, we simulate the outcome of the competition keeping wages unchanged; we call this scenario 'no FFP'. Then we simulate scenarios for four levels of the acceptable deviation, which correspond to the actual implementation scheme, that is, €15 million per season, €10 million per season, $€ 5$ million per season and the 'final' scenario of $€ 5$ million over three consecutive seasons. For each scenario we report the results using the FE and O-P estimates of the contest function. The simulation proceeds in four steps. First, we adapt the budget constraint for each restricted team and work out the payroll under its new budget constraint. We then use these new payrolls to recalculate the points total and revenues for all teams. In this new situation, however, several teams may find that their choice of payroll is not the optimal choice and consequently this vector of payrolls is not a Nash-equilibrium of our stylized model. In a third step we therefore adapt all payrolls, using either the assumption of the 'profit' or the 'win' oriented owners, which have been outlined in Section 4.1. We then recalculate the end-of season points and revenues. This again creates a situation in which certain clubs should adapt their payrolls. So, in a fourth step we simply repeat steps two and three until we reach a new equilibrium where each club simultaneously chooses its optimal payroll, given

22 The root mean squared error is calculated as the square root of the average of the squared difference between the predicted and actual values, i.e. $R M S E=\sqrt{\left.E\left[(\hat{W}-W)^{2}\right)\right]}$. The mean absolute error is given by $M A E=E[|\hat{W}-W|]$. The advantage of these measures compared to the mean squared error is that they are measured in the same units as the basic problem, making them easier to interpret. 


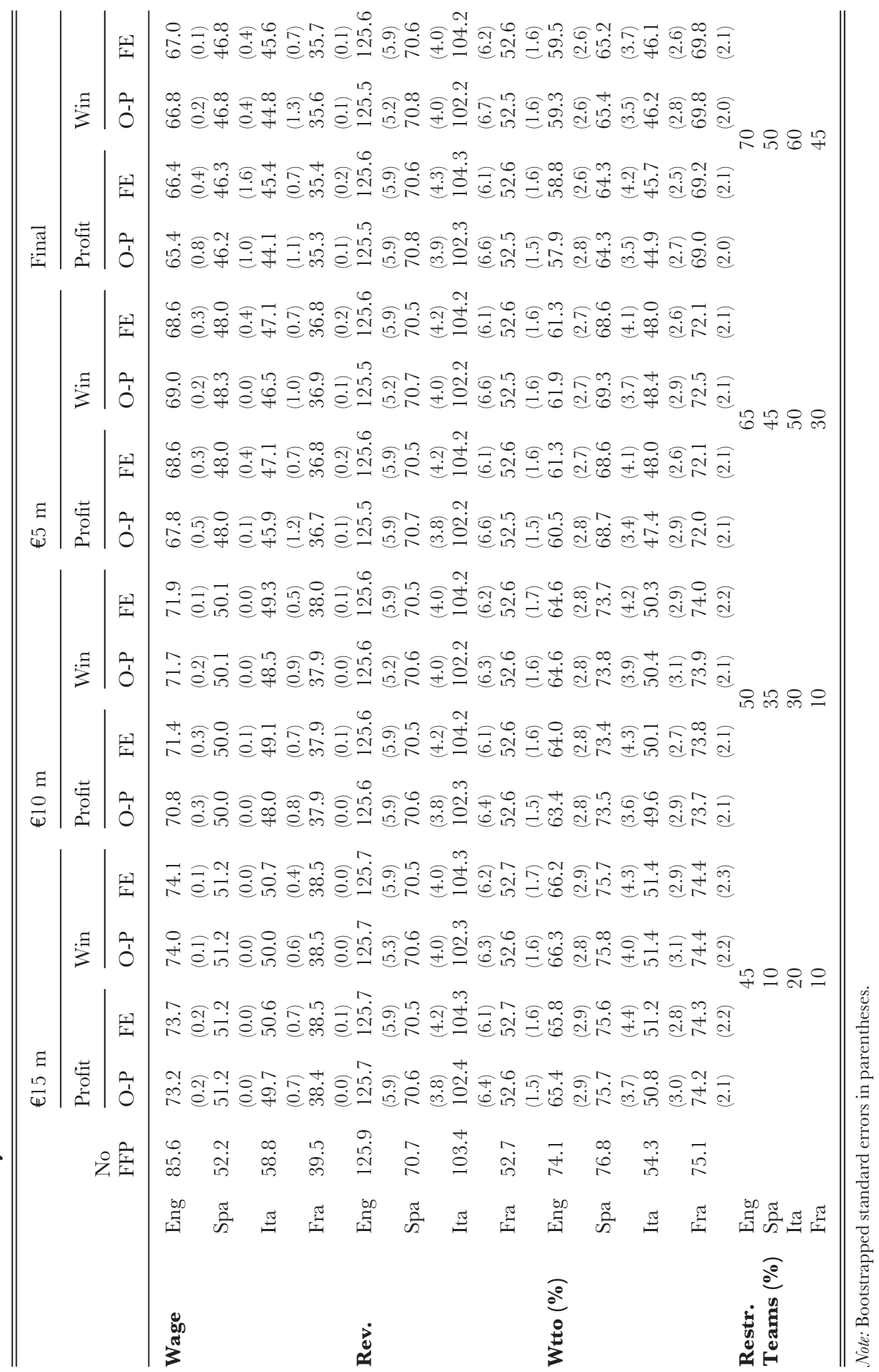


the scenario we are simulating. We refer interested readers to Appendix section A2 for more details on this procedure.

Table 6 reports a summary of the simulation results for the most important financial variables in all leagues. The bottom panel shows that the English Premier League has by far the most restricted teams in every scenario, a result which is most stunning for the relatively mild regimes. In our view, this is mostly a consequence of the economic clout of the league. Whereas most English clubs are able to handle an average loss of $€ 15$ million over consecutive seasons, this is clearly not sustainable for smaller clubs in France, Italy and Spain. As the regime grows more restrictive over time, obviously more teams find themselves restricted by the break-even rule. Also note that in the final regime more than half of the teams over all four leagues would be affected directly by the break-even rule, which underlines its potentially far-reaching impact on the European football industry.

In the top panel of Table 6 we report the average payroll for each league under all scenarios. The standard error for the simulation result is given in parentheses. The results show that as a consequence of the break-even rule payrolls decline significantly across all leagues and regimes. Naturally, we find larger declines when the regulatory regime is more stringent. For the mildest regime, the range goes from a $€ 1$ million decline for France and Spain up to a fall of €11-12 million for England. In relative terms, however, the reduction in Italian wage bills is comparable to England (around $-14 \%$ ). A similar picture emerges for the more stringent regimes, with the drop in French wages reaching around $€ 4$ million, whereas in England wages could go down by as much as $€ 19$ million. Here the relative decline is slightly larger in Italy $(-24 \%)$ than England (-22\%), with Spain and France experiencing a drop of around $-10 \%$. Comparing across different scenarios shows that the 'profit'-scenario always leads to lower average payrolls, which is intuitive since owners are assumed to take more money out of the league. The difference between scenarios is often significant as compared to the bootstrapped standard errors, but not hugely important in economic terms with maximum spreads of around $€ 1.5$ million.

Team revenues are depicted in the second panel of Table 6. The results of our simulation suggest that average revenues would not be significantly affected by the break-even constraint. Still, specific teams may see large decreases in their individual earnings, as their on-field performance deteriorates. At the league level, however, these drawbacks are levelled out against the extra revenues other teams in the league enjoy through the surge in their sports performance. Looking across the different scenarios, it appears that the tightening of the regulatory regime has a very limited impact on the level of average revenues.

In the third panel of Table 6 we report the effect of the break-even rule on the average wage-to-turnover (wtto) ratio in the league. This metric is simply the ratio of the total wage bill of a team divided by its total revenues. It is a good indicator for the profitability of football clubs, as in most cases wages constitute by far the most important cost driver for a club. The introduction of the break-even constraint 


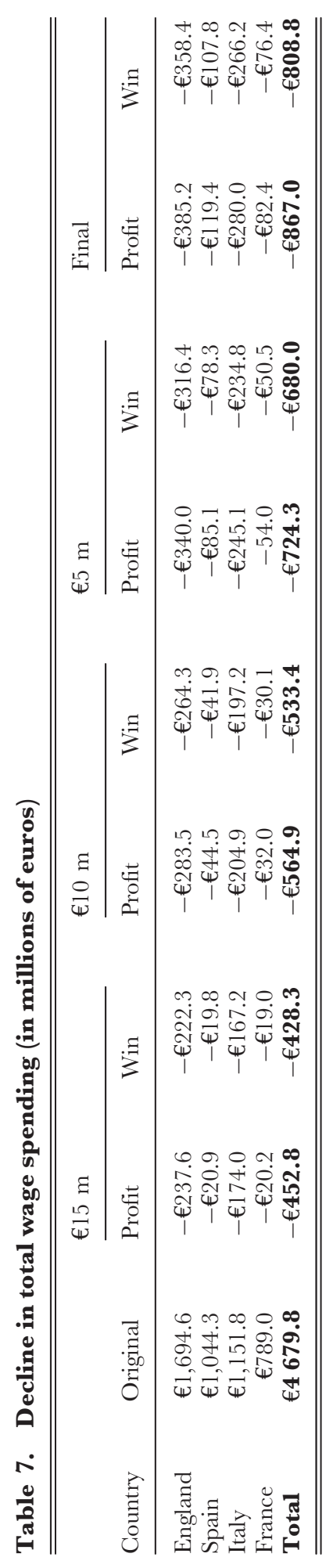


unambiguously lowers the wtto in all leagues. Naturally, we find the decline to be largest in the more stringent regimes, where wage bills decrease most. In the mildest regime, for example, only England sees a significant drop of around 8\%. In the final scenario, however, all leagues experience large and significant declines of their average wtto ratio.

In Table 7 we specifically highlight one result from our simulation exercise. ${ }^{23} \mathrm{We}$ show the decline in total wage spending over all clubs in the top leagues in our sample, which we interpret as a measure of the economic rents in the industry which would be shifted from the players (and tax authorities) to the owners due to the break-even rule. Clearly, the impact of FFP would be considerable. Even in the mildest regime and with the most conservative assumptions, the break-even rule shifts more than $€ 400$ million back to the owners, which is about $10 \%$ of the laissez-faire wage payments. In the final regime this would double to a reduction of over $€ 800$ million in wage payments. The biggest burden would fall on the Premier League players, who incur the major part of this reduction.

As discussed above, the protection of competitive balance is a major argument to justify competition restraints in professional sports. In Table 8 we therefore look at the effects of the break-even rule on the distribution of points won in the league. We simulate the introduction of a North-American style salary cap alongside the FFP results, such that we are able to compare the competitive balance impact of both types of regulation. Here we define a salary cap as a uniform maximum level for club-wide payrolls across the league. This is a simplification in comparison to most US cap systems, which also contain provisions related to individual player remunerations, but this type of data is unavailable for European football. As the top panel of Table $8^{24}$ shows, we have selected levels for the salary cap which lead to similar reductions in average payroll as the FFP regimes in order to make the results more comparable.

The second and third panel depict the average and maximum shift in end-of-season points in comparison with the laissez-faire equilibrium. In the less stringent regimes we find the significant point shifts in England and Italy, while Spain and France see very limited movements in their league results. The more stringent break-even constraints would significantly alter the end-of-season points in all leagues. In every scenario the impact in England and Italy would be far larger than in France and especially Spain. The bottom panel of Table 8 shows the standard deviation of points, which may be interpreted as a measure of seasonal competitive balance, that is, the tension of the sports competition within one season. ${ }^{25}$ Overall the break-even rule leads to slight improvements of the balance, except for Spain. In the least stringent regimes

23 These tables are based on the O-P results; the FE results are very similar.

24 These results are from the 'win' scenario using the O-P estimates. The salary cap exercise uses the same estimates and assumptions concerning owner behaviour.

25 Seasonal competitive balance refers to the tension of competition over the course of a season, i.e. closeness of the pennant race, relegation fight etc. In the literature authors have typically distinguished between match, seasonal and inter-seasonal competitive balance. 


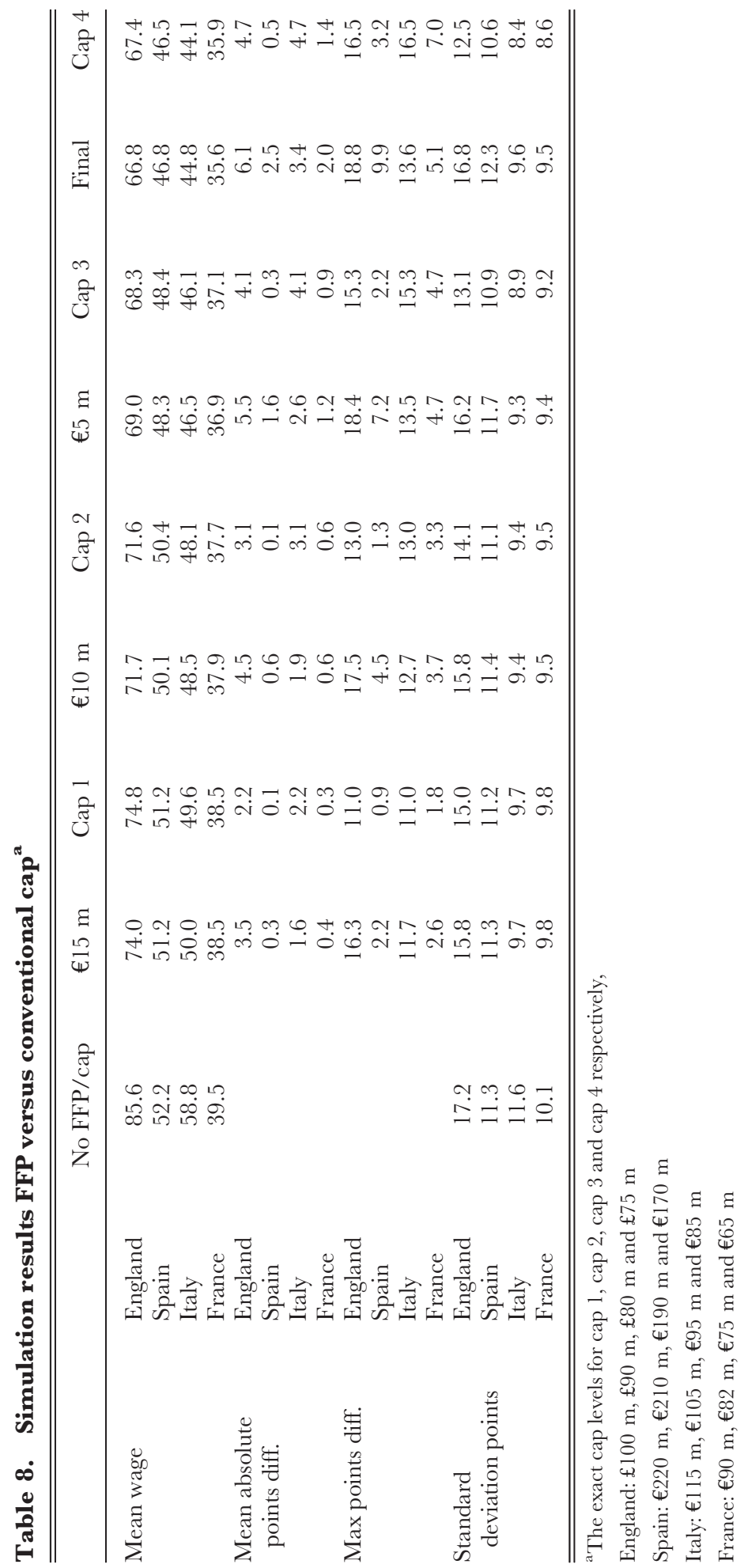


Table 9. End-of-season table, EPL 2010

\begin{tabular}{|c|c|c|c|c|c|c|c|c|c|c|c|}
\hline \multirow{2}{*}{$\frac{\text { Team }}{\text { Man United }}$} & \multirow{2}{*}{$\frac{\text { Real }}{85}$} & \multicolumn{2}{|c|}{ No FFP } & \multicolumn{2}{|c|}{$€ 15 \mathrm{~m}$} & \multicolumn{2}{|c|}{$€ 10 \mathrm{~m}$} & \multicolumn{2}{|c|}{$€ 5 \mathrm{~m}$} & \multicolumn{2}{|l|}{ Final } \\
\hline & & 83.0 & (3.3) & 84.8 & (3.2) & 84.7 & (3.2) & 85.0 & (3.1) & 85.3 & (3.1) \\
\hline Arsenal & 75 & 76.8 & (3.2) & 79.6 & (3.1) & 80.3 & $(3.0)$ & 81.4 & (2.9) & 82.3 & $(2.8)$ \\
\hline Chelsea & 86 & 76.5 & $(2.5)$ & 70.7 & $(2.6)$ & 70.6 & $(2.6)$ & 70.8 & $(2.6)$ & 71.3 & $(2.6)$ \\
\hline Liverpool & 63 & 75.9 & (2.1) & 75.7 & (2.2) & 75.5 & (2.2) & 75.6 & (2.2) & 75.9 & (2.2) \\
\hline Man City & 67 & 75.8 & (2.2) & 59.5 & (3.3) & 58.3 & $(3.5)$ & 57.4 & (3.4) & 57.0 & (3.4) \\
\hline Aston Villa & 64 & 62.7 & $(1.6)$ & 58.3 & $(1.5)$ & 57.1 & $(1.6)$ & 56.2 & $(1.6)$ & 55.9 & $(1.6)$ \\
\hline Tottenham & 70 & 53.8 & $(1.2)$ & 56.8 & (1.3) & 57.7 & $(1.4)$ & 59.1 & (1.7) & 60.4 & $(1.8)$ \\
\hline Everton & 61 & 49.9 & (1.9) & 52.7 & (2.1) & 53.6 & $(2.3)$ & 54.9 & $(2.5)$ & 56.2 & $(2.7)$ \\
\hline Fulham & 46 & 46.4 & $(1.0)$ & 49.1 & $(1.2)$ & 49.7 & (1.3) & 48.6 & $(1.5)$ & 48.2 & $(1.6)$ \\
\hline Stoke & 47 & 44.8 & $(2.4)$ & 47.3 & $(2.5)$ & 48.1 & $(2.6)$ & 49.4 & (2.7) & 49.8 & $(2.8)$ \\
\hline Sunderland & 44 & 44.6 & (1.3) & 42.8 & $(1.5)$ & 40.8 & $(1.6)$ & 38.8 & $(1.7)$ & 37.6 & $(1.7)$ \\
\hline West Ham & 35 & 44.1 & (1.3) & 37.8 & $(1.7)$ & 34.8 & $(5.3)$ & 31.1 & (11.3) & 27.8 & (13.4) \\
\hline Blackburn & 50 & 43.1 & $(1.0)$ & 45.7 & $(1.2)$ & 46.6 & (1.3) & 48.0 & $(1.7)$ & 49.3 & $(1.9)$ \\
\hline Bolton & 39 & 42.7 & $(0.9)$ & 41.7 & $(0.9)$ & 39.4 & $(1.0)$ & 37.1 & (1.2) & 35.7 & (1.3) \\
\hline Birmingham & 50 & 39.2 & (1.1) & 41.9 & (1.1) & 42.9 & $(1.2)$ & 43.4 & $(1.6)$ & 42.5 & $(1.8)$ \\
\hline Hull & 30 & 36.7 & $(1.5)$ & 39.2 & $(1.6)$ & 40.0 & (1.7) & 40.7 & $(2.0)$ & 40.0 & (2.2) \\
\hline Wigan & 36 & 35.8 & (1.7) & 38.1 & $(1.8)$ & 38.9 & $(2.0)$ & 38.2 & (2.2) & 37.4 & (2.2) \\
\hline Wolverhampton & 38 & 35.5 & $(1.7)$ & 38.5 & $(1.6)$ & 39.6 & $(1.8)$ & 41.2 & (2.3) & 42.8 & $(2.5)$ \\
\hline Burnley & 30 & 27.6 & $(1.6)$ & 29.9 & $(1.5)$ & 30.7 & $(1.5)$ & 32.2 & (1.9) & 33.5 & $(2.1)$ \\
\hline Portsmouth $^{\mathrm{a}}$ & n.a. & 50.0 & (1.7) & 52.4 & $(1.8)$ & 53.1 & (1.9) & 54.2 & $(2.0)$ & 55.3 & $(2.2)$ \\
\hline
\end{tabular}

Notes: Bootstrapped standard errors in parentheses. ${ }^{\mathrm{a}}$ The accounts for Portsmouth are missing due to filing for insolvency in the 2010 season. We imputed data for the 2009 season and assumed a fixed wage bill throughout all regimes. We consequently excluded them from the calculation of the summary financial results and report their result only for completeness.

the break-even rule might improve competitive balance because it mainly restricts the large teams. This appears to be the case in Italy and England. As the regime becomes more stringent, smaller teams are affected as well and the balance starts to deteriorate again. A salary cap on the other hand unequivocally leads to more balanced competition and if the cap is made more stringent, the balance increases more. Furthermore, we find that the cap leads to a more balanced competition than FFP in all scenarios.

To gain insight in which teams are losing and which are winning points because of the break-even constraint, Table 9 depicts the full simulated points table for the English Premier League. ${ }^{26}$ A first thing to note is that for most teams the impact of the break-even constraint on their predicted points is fairly modest, even though the Premier League has the largest average points shift of all leagues. A few teams see a considerable drop in their performance, most notably Manchester City and West Ham, and to a lesser extent Chelsea and Aston Villa. It is no coincidence that Chelsea and Manchester City are the two prime examples of teams where the owner generously subsidizes the operational losses of the team to boost the performance on the field. The performance of the traditional top teams, Manchester United, Arsenal and

26 As the impact of the break-even constraint is felt most in England, we only report full tables for the EPL. The full tables for the other leagues, shown in the Appendix, display largely similar patterns, but in general the effects are smaller. 
Liverpool, is not hampered by the introduction of Financial Fair Play. This finding illustrates another way in which the break-even rule would benefit the incumbent top teams in Europe. The traditional top teams are most often located in the largest local markets and usually enjoy high on-field productivity due to superior scouting, training and coaching abilities. This inevitably leads to sustained dominance on the field if investing in a smaller team's performance by subsidizing operational losses while building the team is not allowed. Absent the possibility to incur losses, it therefore becomes increasingly difficult, if not impossible, for smaller teams to challenge the dominance of the clubs at the top.

Our simple model of league competition shortcuts one important aspect of the European football industry, the migration of talented players between leagues. Unlike in the US major leagues, European football leagues compete with each other for talented players. As players have the possibility to leave the league at any point in time, this means that the total supply of talented players for any individual league is not fixed, but flexible. Consequently, if wage bills were to decline considerably, the total talent stock in the league could go down, lowering fan interest and revenues across the board while making rival leagues relatively more attractive. As we have observed earlier, the one large league which we have not modelled, the German Bundesliga, is unlikely to see its wage levels change significantly since its domestic rules are similar to FFP. We have also observed that the rules are unlikely to be binding on the smaller leagues because the break-even constraint is defined in absolute rather than relative terms. Thus clubs from Germany and the smaller leagues are likely to benefit from FFP in on-the-field play. We argue this is consistent with the interpretation that FFP is intended to preserve the structure of UEFA competition in Europe by allowing clubs from smaller countries to be more competitive while enabling the clubs from larger countries to benefit from lower wage spending. However, given the gap in wage spending between the dominant European teams and clubs from the smaller leagues, we think this effect is likely to be negligible.

\section{CONCLUSION}

Financial Fair Play (FFP) represents an important development in the regulation of football, as it is the first concerted European-wide effort to improve the financial health of Europe's football clubs. Unlike in the US major leagues, where club owners have implemented numerous horizontal restraints, FFP has been instigated by UEFA, which simultaneously acts as the industry's regulator and the organizer of inter-league competition. We have argued that FFP is therefore not a horizontal coordination device, but should be viewed as a type of vertical restraint, which helps UEFA to strengthen its position as a non-governmental regulator while at the same time turning the top European clubs into more profitable ventures.

Our empirical analysis has focused on the break-even rule, which stipulates that clubs should balance their football related costs with their football related revenues. 
This rule represents the most controversial element of the FFP regulations, because it rules out the possibility that outside investors bankroll a club's financial losses. Our simulation results indicate that the break-even rule is a potentially powerful tool to decrease wage spending in the biggest European leagues, without significantly reducing revenues. In particular there is a significant reduction in the wage to turnover ratio, with the strongest impact in England. As such, the break-even rule mimics a US-style salary cap, in that it limits wage bills and improves the profitability of the clubs. In comparison to a salary cap, however, the break-even rule does far less to improve seasonal competitive balance. ${ }^{27}$ Furthermore, the break-even rule protects the success of the traditional big-market top teams, because it reduces the scope for challenges by smaller teams which may be financed by a wealthy owner. Our results therefore show how FFP would shift rents from the players to the owners without delivering gains for consumers in the form of an improvement in the intensity of on-field competition.

As expected, and UEFA have designed the rules with this possibility in mind, legal challenges to FFP are already underway. One issue is whether regulations aimed at eliminating particular types of owners (or restricting how those owners choose to invest in their businesses) are lawful, but this paper has not addressed this issue. The FFP rules on insolvency (no overdues payable, positive net equity and going concern) are not generally viewed as controversial, though it remains to be seen whether they will in reality reduce the incidence of insolvency.

The chances for the break-even rule to pass a competition law challenge seem more questionable in our view. As we have shown, conventional salary caps are a superior device to improve competitive balance in national leagues. The break-even rule may even ossify intra-league competition, because it protects the traditional big market teams from challenges by clubs who are backed by an outside investor. On top of that, we do not see any significant benefit to competitive balance from the point of view of European (inter-league) competition. If the courts conclude that the break-even rule is no more than a rent shifting agreement which brings no obvious benefits to consumers, it is unlikely to survive antitrust scrutiny.

\section{Discussion}

\section{Chiara Fumagalli}

\section{Universitá Bocconi}

This paper performs a detailed assessment of the effects of the introduction of Financial Fair Play regulation in European football. The paper documents that the main effect of such regulation is to limit substantially the club spending for players, with a

${ }^{27}$ While UEFA officials often mention the potential of FFP to improve competitive balance, it is not formally advanced as a rationale for the regulations. 
positive but limited effect on competitive balance (at least more limited as compared to the effect of an explicit salary cap). The way the authors interpret this result is that Financial Fair Play will cement the competitive advantage of incumbent top teams.

I am not entirely convinced by this interpretation of the results. Should we be concerned if Financial Fair Play transfers money from football players to clubs? What we observed in the past, at least in Spain and Italy, is that the government intervened to rescue football clubs that accumulated large losses, either by granting a tax relief or by using other exceptional measures. In this context Financial Fair Play might be welfare beneficial to the extent that it avoids inefficient use of revenues collected from taxpayers. Moreover, football clubs might use the resources saved on wage spending in order to invest in infrastructure for youthful sport activity, or in the deterrence of the violence and racism that plagues football in some European countries. UEFA itself might invest more in these activities if - as claimed in the paper - lower wage spending by clubs implies that UEFA manages to distribute to clubs a lower share of the income it generates, thereby retaining a larger share for the projects it wishes to develop. More generally, I would have appreciated a deeper discussion of the reasons why the transfer of money from football players to clubs that the paper documents is welfare detrimental.

Moreover, I have some concerns about the model. First, at the last stage of the game, the outcome of a given match is assumed to depend on the relative wage spending of the two teams - which captures the quality of the players hired by the teams and by the relative productivities of the clubs. But the authors do not allow the outcome of a match to depend on the effort exerted by players in that match, which in turn depends on many factors that are match specific. For instance, team $j$ has a much higher probability of winning if the players of the opposing team are inattentive because a few days after they have to play a crucial match. Note that, in principle, match-specific effort can be measured, for instance by the grades obtained by players in specialized newspapers or by the number of metres run by players. I acknowledge that collecting such data might be outside the scope of this paper, but it should be outlined that disregarding this aspect in the estimation of productivities is problematic.

Second, a profit-maximizing owner is assumed to pocket all the extra money that the team can spend when Financial Fair Play constrains the behaviour of other teams and forces them to reduce their spending. Why doesn't the profit-maximizing owner re-optimize the budget choice when Financial Fair Play is introduced? It might be optimal to spend part of the extra money and pocket the remaining part, thereby increasing the probability of winning and thus the revenues collected and ultimately profits. This alternative assumption might affect the distribution of points at the end of the season and the ability of smaller teams, that are run efficiently, to challenge top positions in national leagues.

Finally, the simultaneous choice of wage-spending is likely to generate multiple equilibria, possibly displaying different properties in terms of dispersion of points and contestability of top positions. Indeed, the existence and uniqueness of the Nash equilibrium in wage spending is not demonstrated in the paper. 
As a consequence, I am not convinced that the results of the paper are robust enough to claim that the effect of the introduction of Financial Fair Play is to reinforce the position of dominant teams.

\section{Catherine Thomas}

\section{London School of Economics}

This paper tackles the question of how new regulations introduced to European football in 2010 will affect teams' financial and sporting performance. It introduces a structural model to estimate how the regulation will impact league outcomes through its impact on players' wages.

The paper should appeal to all those interested in football and the economics of sport. For economists who study regulation and industry structure, it raises the questions of how to regulate sport, where teams face different objectives than firms and, unlike in a typical industry, competitive interactions are necessarily zero sum (one team wins, one loses, or they both draw).

In describing the Financial Fair Play regulations, the authors make some carefully thought out inferences about its main consequences. The regulation does not explicitly set out to limit team payroll, but the break-even constraint appears likely to have this effect. The paper then focuses only on this consequence.

The legality of the FFP regulations is also discussed here. Limits to team payrolls allow the clubs to retain a larger share of rents, acting as a vertical restraint. The paper mentions how a complaint has already been brought to the European Commission, on behalf of a player agent (who retains a share of his player's wages). The competition law context frames the empirical exercise conducted in the paper, which estimates whether there are benefits to the regulations that might help offset anti-competitiveness concerns.

The empirical work simulates the outcomes of European football leagues under the regulation. To do this, the authors predict the outcomes of all the games in a season. This is an ambitious challenge. It will be interesting to see how well the model performed using actual post-regulation game outcomes!

A key part of the model is the contest function, where the game outcome is a function of relative payrolls, team effects (either fixed effects or 'productivity'), a home team advantage, and a game-specific error term. Game outcomes, and the points earned by each team, determine club revenues and, hence, whether the constraint on team payroll binds. In the simulation, the number of points scored by each team is predicted under these parameter estimates and different payroll levels.

One concern I have with the empirical work is that, in the counterfactuals, the authors maintain the structural relationship between relative wages and game outcomes that was estimated prior to the regulations. Implicit in this approach is that players will exert less effort when earning lower wages. I think it is quite likely that the regulation changes the player's optimization problem in a more fundamental way. While their salaries may fall, their outside options (pay-offs from moving to another 
team) have also fallen, and it is not clear how this affects their performance. It is also likely that, in general, players try hard to maximize their own lifetime pay-offs, which may include financial and non-financial rewards.

A second concern I have is with the Olley-Pakes measure of productivity. First, is it clear that there is the type of simultaneity problem here that Olley-Pakes addresses?

If team salaries are set before the season-specific team productivity draw is observed, then there is no reason to anticipate a bias in the estimated coefficients, and productivity could be measured as the OLS residual. The paper does not discuss the timing of the player contracting process.

In the Olley-Pakes method undertaken here, manager tenure and fixed assets are described as instruments for unobserved team productivity, being correlated with productivity and having no direct effect on outcomes. However, this methodology requires finding an observed team-specific control variable that is correlated with productivity over time. If the main advantage of this approach over fixed effects is to allow team effects to vary over time, I think it would be more appropriate to use the data differently. For example, a manager may be fired after a bad season, so manager tenure in time $t+1$ would be a better proxy for productivity in period $t$. Similarly, the change in fixed assets (i.e. investment) between $t+1$ and $t$ is more likely to be correlated with the unobserved productivity shock in period $t$ rather than the value of the fixed assets, which is a state variable determined by past activity.

Last, the fact that these observations are pairwise may present some problems in both the fixed effects and Olley-Pakes specifications. For example, can we justify the i.i.d. assumption on the error term given that the same team appears in multiple observations? In addition, teams often meet each other twice in the same league season. Football commentators, at least, give the impression that history matters in subsequent game outcomes.

Finally, another part of the paper presents outcomes under different regulatory regimes, specifically, the US salary cap (of a uniform maximum team salary). The authors predict that this approach would increase competitive balance in the leagues, which FFP fails to achieve in their estimations. This is a very thought-provoking finding and should provide some relevant input to the ongoing debate in the EU about regulating this industry.

\section{Panel discussion}

Returning to the welfare topic raised by Chiara Fumagalli, Andrew Ellul questioned why one should care about the direction in which rents are transferred as a result of financial fair play. For example, if rents get transferred from players to clubs, and clubs use the money to invest more in youth football, the overall welfare implications might be positive. Lutz Kilian was under the impres- 
sion that restoring competitive balance across Europe has always been one of the primary targets of the UEFA. He stated that this matter is not addressed in the authors' study which only focuses on competitive balance within the different national leagues. Second, Kilian argued that the model does not incorporate non-linearities/discontinuities arising from the difference between qualifying for the Champions League, qualifying for the Europa League, and not qualifying for either, which matter beyond the simply objective of maximizing points. He noted that this distinction has important implications for the club's budget constraint in the following season. Alex Michaelides asked if the authors could elaborate on the politics driving financial fair play. He contended that it could be construed as financial 'unfair' play in the sense that, as Ellul mentioned, it maintains the oligopoly structure of the incumbent top clubs in the national leagues.

On the issue of different types of owners leading to different findings, Stefan Szymanski said that further examination of this matter (randomizing the objectives) should not be problematic. Szymanski clarified that it is difficult to provide an exact definition of a 'sugar daddy' and therefore it is a demanding task to identify the precise number of clubs run by such owners. He also reiterated that the general consensus in the literature is that owners in America are profit maximizers whereas those in Europe are win maximizers. Szymanski was highly sceptical about accounting for match-specific effort (on which an enormous amount of data exist) as one would generally ruminate on this issue in an asymmetric information setting with an underlying principal-agent model. He thought that such frameworks lack relevance in sport. On the other hand, he did accept that one could garner data on players' rest times or kilometres run per game and investigate whether that imparts an effect.

On the welfare implications, Szymanski noted that the break-even financial fair play regulation is, just like Bosman was, a clear violation of European competition law (in the sense that it transfers rents away from players). Szymanski had doubts about broader welfare benefits as UEFA does not unequivocally convey their overall objective. As far as the competitive balance objective is concerned, he stressed that it is not even clear according to the literature that society prefers such balances in practice. Regarding the politics of financial fair play, Szymanski highlighted that UEFA was primarily concerned with the insolvency of small clubs across Europe since this reflected poorly on them as a governing regulatory body. At the same time, Michel Platini's election was based on the premise that he would endeavour to aid the smaller clubs. According to Szymanski, the sole regulation of their solvency would have been perceived as not doing anything. This is why UEFA introduced the break-even constraint. As Szymanski argued, by doing so the body attacked the 'sugar daddies', which are disliked by the vast majority, and made it seem as if they were striking at the big powers of European football. 


\section{APPENDIX}

In this appendix we first provide additional technical details on the estimation and simulation methods we report in the paper. Secondly, we provide additional simulation results for on-field competition in Spain, Italy and France.

\section{A1. Equilibrium}

In our stylized model we assume that a Nash-equilibrium vector of payrolls $p_{t}^{*}$ exists, where all owners choose a best-response budget constraint given their utility function and all managers consequently set optimal payrolls. It is not obvious, however, that (a) such an equilibrium exists and (b) it is unique over the possible set of payrolls. To examine this issue we have created a program which starts from any arbitrary payroll vector and searches for each manager's best-response payroll using the estimated elements of our model, that is, the contest function (Equation 1), the revenue function (Equation 2), the observed non-payroll cost and the estimated budget constraints of the owners. We went through this procedure using 1,000 independent draws for the initial payroll vector from the interval [€10 m, €190 m] or [£10 m, £190 m] for England. In all leagues we found that (a) a fixed point for the payroll vector exists if we disallow negative payrolls ${ }^{28}$ and (b) this fixed point is always equal to the reported laissez-faire equilibrium. This exercise does not provide formal proof for the uniqueness or existence of a Nashequilibrium for all possible values of the model parameters. Yet, we argue that it supports our choice for the reported simulation results, as it shows they appear to be the only equilibrium of the estimated model, which falls within realistic boundaries for the payroll vector.

\section{A2. Estimation procedure}

A2.1. Contest function. To estimate the parameters of the contest function in Equation (1) we first take logs of the expression for $y_{i j t}^{*}$, which gives us:

$$
\log \left(\gamma_{i j t}^{*}\right)=\beta_{d} \log \left(p_{i t}\right)-\beta_{d} \log \left(p_{j t}\right)+\log \left(\omega_{i t}\right)-\log \left(\omega_{j t}\right)+\varepsilon_{i j t} .
$$

We then assume the error term $\varepsilon_{i j t}$ follows an i.i.d. normal distribution. This allows us to estimate the entire contest function by means of a standard ordered probit. We apply the delta method to rescale the standard error on the thresholds.

\footnotetext{
28 Negative payrolls would cause the calculation of probabilities using the contest function to be infeasible.
} 
As set out in the main text we use an instrumental variable approach (along with fixed effects) to deal with the omitted variable bias, which may arise from unobserved team productivity. In doing so, we use a fourth order polynomial of the logarithm of manager tenure and the book value of tangible fixed assets. In this approach the choice of instruments for productivity is crucially important. We have therefore tested a number of alternative instruments using the English dataset. More specifically, we tested total employment (playing and non-playing staff), cash holdings and investments in tangible assets. For various reasons ${ }^{29}$ these alternative instruments generated a less accurate fit, which led to the current choice of instruments.

To eliminate any feedback effects from the contest results on wage spending, we use the two-stage estimator for non-linear models introduced by Rivers and Vuong (1988). In the first stage this procedure requires to regress the potentially endogenous variables on all exogenous variables in the model plus a set of instruments. The residuals of this OLS estimation then enter into the second stage, which is the estimation of the non-linear model including the potentially endogenous variable. In our case, the first stage regresses current wage spending on wage spending in the previous season, dummies to indicate whether the team was promoted or relegated, and all second stage variables. The second stage is then the ordered probit estimation of Equation (A1) including the first stage residuals. To obtain consistent standard errors we bootstrap the two-stage procedure using 200 iterations. This procedure is used to establish all results reported in Table 2, irrespective of the approach towards unobserved firm level productivity.

A further concern in the estimation of Equation (A1) is that effort in any individual contest is inherently unobservable in our setting. We approximate the efforts by the total wage spending over the season, which is fixed over all games. It is conceivable, however, that effort varies considerably across games, either by coaches fielding less valuable players or by players putting in less effort on the pitch. A classic example are mid-table clubs fielding less competitive teams, when they find themselves unable to qualify for European football, but safe from relegation a couple of games before the season ends. To check how sensitive our estimation results are to this type of effects, we estimate the contest function on a sub-sample of games played before April. This excludes the last 5 to 6 games, which are most affected by end-of-season incentive effects. We found the estimates to be very similar to the ones reported in Table 2, which seems to confirm the robustness of our findings vis-à-vis this effort effect.

29 For example, investments were taken to be the increase in the level of tangible fixed assets, which is an inaccurate measure of investments. Other authors (e.g. Olley and Pakes, 1996) have preferred the use of survey data over accounts data. These are, however, not available in our setting. 


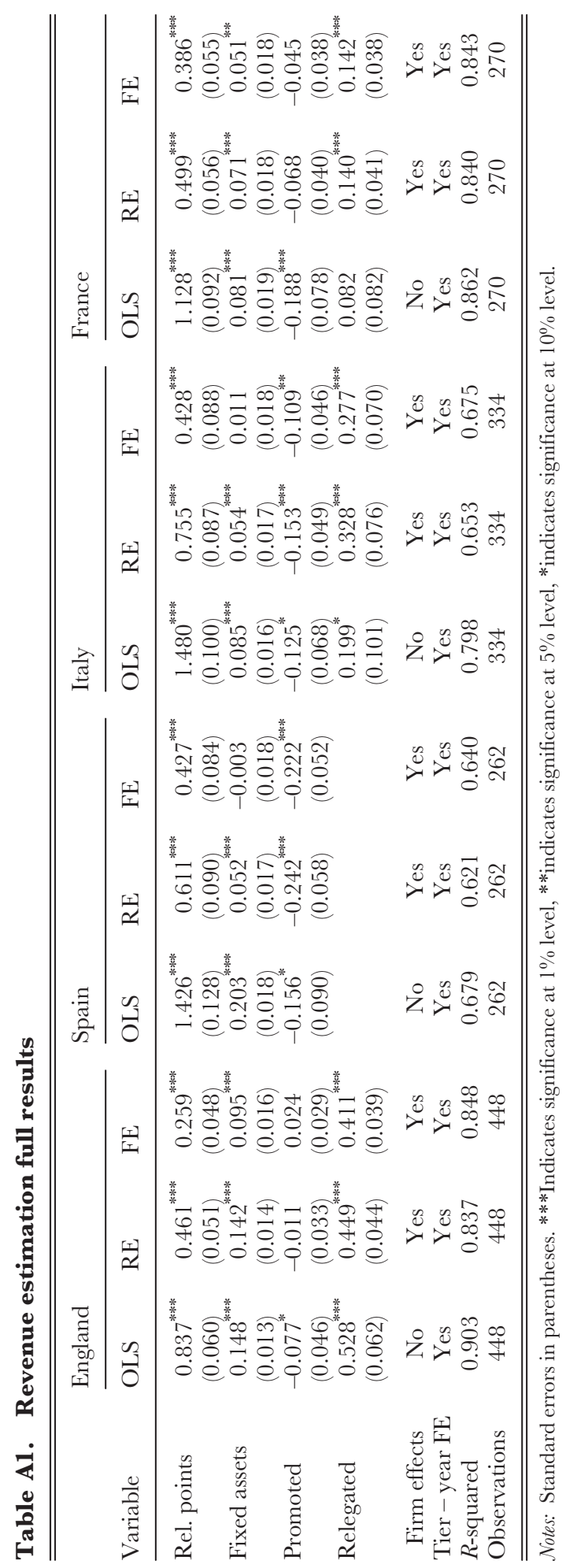



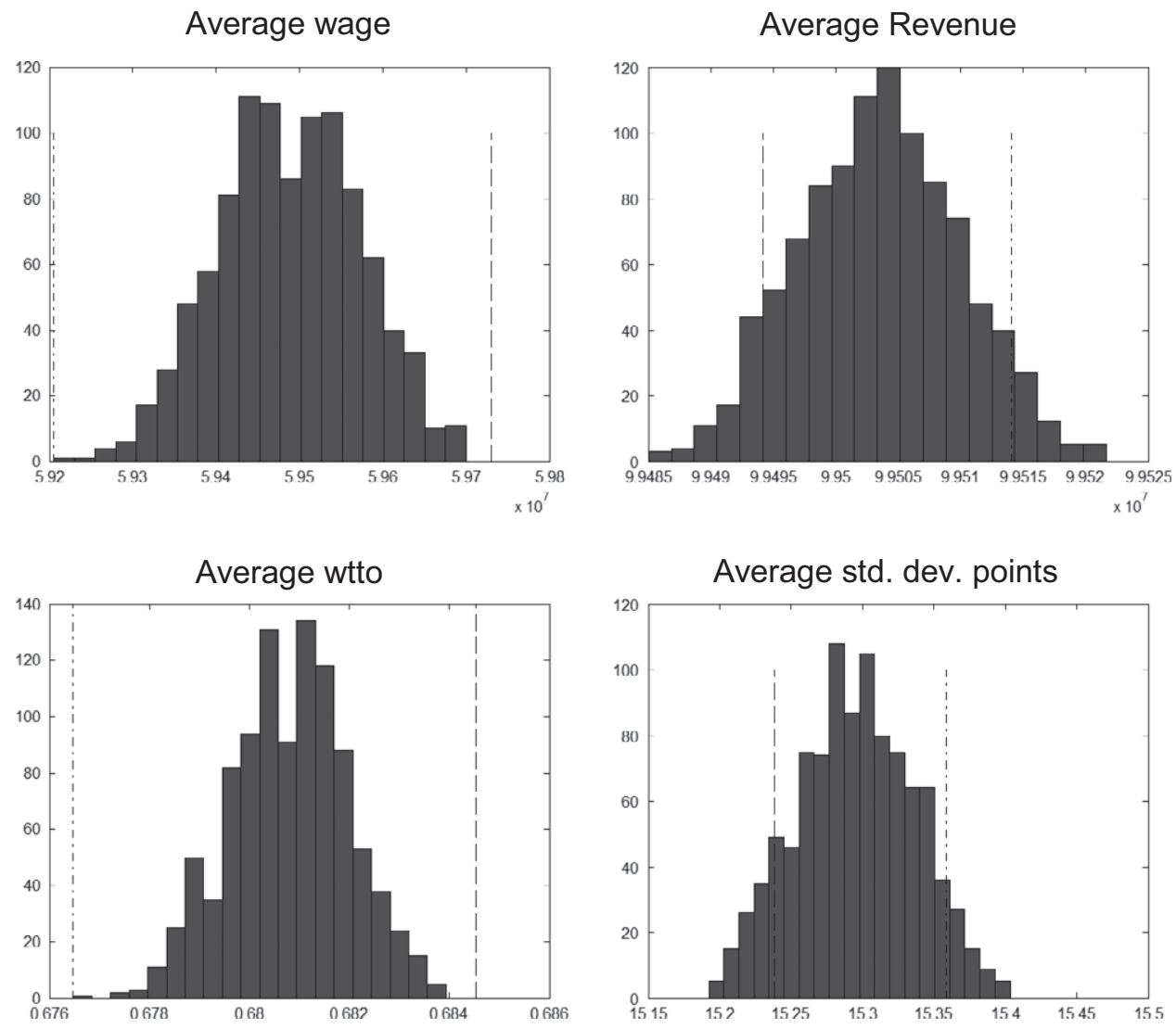

Figure A1. Simulation results with randomized win- and profit-oriented owners Notes: These results depict England under the $€ 15 \mathrm{~m}$ regime. The dashed line represents the pure 'win'-scenario, the dot-dash line the 'profit'-scenario. On the $y$-axis is the number of simulation (out of 1,000 ), on the $x$-axis the relevant outcome, nominated in UK pounds. Other leagues and regimes led to completely similar results.

A2.2. Revenue function. A second equation we need to estimate is the revenue function given in (2). We estimate this model using pooled OLS, random and fixed effects for each team. Table Al gives the result for all leagues. Clearly, the estimated effect of points obtained and assets goes down with the introduction of team-specific controls, which is a fairly standard result in this type of models. Based on Hausman test results, we choose to report the fixed effects models and use them for the simulations in the paper. In the final model we introduce an additional variable for the English clubs to control whether they were the ultimate parent company in case they are part of a holding, as this might affect the book value of tangible fixed assets. To keep as close to the FFP rules as possible we also subtracted revenues, which were explicitly labelled 'non-football' in the accounts. ${ }^{30}$

30 There were only three such cases, Arsenal (property development), Bolton Wanderers (hotel) and Sheffield United (conferences). 
Table A2. Points table for all FFP scenarios using O-P simulation approach, Spain 2011 season

\begin{tabular}{lllllllllllll}
\hline \hline Team & Real & \multicolumn{2}{l}{ No FFP } & \multirow{2}{*}{$€ 15 \mathrm{~m}$} & \multirow{2}{*}{$€ 10 \mathrm{~m}$} & & \multirow{2}{*}{$€ 5 \mathrm{~m}$} & & \multicolumn{3}{c}{ Final } & \\
\hline Real Madrid & 92 & 81.0 & $(3.2)$ & 81.1 & $(3.2)$ & 81.4 & $(3.2)$ & 82.0 & $(3.2)$ & 82.7 & $(3.9)$ \\
Barcelona & 96 & 76.8 & $(2.8)$ & 76.3 & $(2.8)$ & 76.4 & $(2.8)$ & 76.8 & $(2.8)$ & 77.4 & $(3.3)$ \\
Valencia & 71 & 65.6 & $(5.0)$ & 65.7 & $(5.0)$ & 65.3 & $(5.0)$ & 64.9 & $(5.0)$ & 65.0 & $(5.6)$ \\
Atlético Madrid & 58 & 57.6 & $(1.7)$ & 57.7 & $(1.8)$ & 57.4 & $(1.7)$ & 57.1 & $(1.7)$ & 57.3 & $(2.7)$ \\
Athletic Club & 58 & 56.1 & $(2.2)$ & 56.3 & $(2.2)$ & 56.6 & $(2.2)$ & 57.4 & $(2.3)$ & 58.3 & $(2.9)$ \\
Espanyol & 49 & 54.8 & $(2.5)$ & 55.0 & $(2.5)$ & 55.3 & $(2.5)$ & 56.1 & $(2.4)$ & 55.6 & $(3.5)$ \\
Villarreal & 62 & 54.1 & $(1.7)$ & 54.2 & $(1.7)$ & 54.5 & $(1.7)$ & 54.6 & $(1.7)$ & 54.6 & $(2.6)$ \\
Sevilla & 58 & 53.0 & $(1.7)$ & 53.2 & $(1.7)$ & 53.5 & $(1.8)$ & 54.3 & $(1.9)$ & 55.2 & $(2.6)$ \\
Málaga & 46 & 50.1 & $(3.8)$ & 50.3 & $(3.8)$ & 49.7 & $(3.7)$ & 49.1 & $(3.7)$ & 48.9 & $(3.7)$ \\
Getafe & 44 & 48.9 & $(2.6)$ & 49.0 & $(2.6)$ & 49.4 & $(2.6)$ & 50.2 & $(2.6)$ & 50.4 & $(2.9)$ \\
Deportivo LC & 43 & 48.6 & $(2.0)$ & 48.8 & $(2.0)$ & 49.1 & $(2.0)$ & 50.1 & $(1.9)$ & 51.2 & $(3.3)$ \\
Real Zaragoza & 45 & 47.5 & $(1.5)$ & 45.3 & $(1.5)$ & 43.0 & $(1.7)$ & 40.2 & $(2.2)$ & 37.6 & $(3.1)$ \\
Real Sociedad & 45 & 47.2 & $(1.2)$ & 47.3 & $(1.2)$ & 47.7 & $(1.2)$ & 48.5 & $(1.1)$ & 49.5 & $(2.4)$ \\
Osasuna & 47 & 46.4 & $(1.6)$ & 46.6 & $(1.6)$ & 46.9 & $(1.6)$ & 47.7 & $(1.5)$ & 48.6 & $(2.6)$ \\
Hércules & 35 & 45.0 & $(1.6)$ & 45.1 & $(1.6)$ & 44.4 & $(1.6)$ & 40.8 & $(1.9)$ & 36.8 & $(2.4)$ \\
Sporting Gijón & 47 & 44.7 & $(3.1)$ & 44.9 & $(3.1)$ & 45.2 & $(3.1)$ & 46.1 & $(3.0)$ & 47.1 & $(3.6)$ \\
Levante & 45 & 43.7 & $(2.9)$ & 43.8 & $(2.9)$ & 44.2 & $(2.8)$ & 45.1 & $(2.7)$ & 46.1 & $(3.6)$ \\
Racing Santander & 46 & 43.4 & $(1.1)$ & 43.5 & $(1.1)$ & 43.7 & $(1.1)$ & 41.2 & $(1.2)$ & 38.9 & $(2.8)$ \\
Mallorca & 44 & 42.0 & $(1.6)$ & 42.1 & $(1.6)$ & 42.5 & $(1.5)$ & 43.3 & $(1.5)$ & 44.3 & $(2.5)$ \\
Almería & 30 & 37.9 & $(1.6)$ & 38.0 & $(1.6)$ & 38.4 & $(1.6)$ & 39.2 & $(1.5)$ & 40.2 & $(2.4)$ \\
\hline \hline
\end{tabular}

Table A3. Points table for all FFP scenarios using O-P simulation approach, Italy 2011 season

\begin{tabular}{|c|c|c|c|c|c|c|c|c|c|c|c|}
\hline \multirow{2}{*}{$\begin{array}{l}\text { Team } \\
\text { Inter }\end{array}$} & \multirow{2}{*}{$\begin{array}{l}\text { Real } \\
76\end{array}$} & \multicolumn{2}{|c|}{ No FFP } & \multicolumn{2}{|c|}{$€ 15 \mathrm{~m}$} & \multicolumn{2}{|c|}{$€ 10 \mathrm{~m}$} & \multicolumn{2}{|l|}{$€ 5 \mathrm{~m}$} & \multicolumn{2}{|l|}{ Final } \\
\hline & & 77.0 & (3.1) & 65.2 & (3.1) & 64.2 & (3.2) & 63.4 & (3.4) & 63.3 & (3.3) \\
\hline Milan & 82 & 75.5 & (2.3) & 72.7 & (2.1) & 72.4 & (2.1) & 72.5 & (2.1) & 72.9 & (2.2) \\
\hline Roma & 63 & 66.5 & $(1.8)$ & 67.0 & $(1.8)$ & 66.4 & $(1.8)$ & 66.1 & $(1.8)$ & 66.2 & $(1.8)$ \\
\hline Juventus & 58 & 58.2 & $(8.7)$ & 56.2 & $(8.8)$ & 55.6 & (o.9) & 55.4 & $(8.9)$ & 55.7 & (8.9) \\
\hline Napoli & 70 & 56.9 & (1.4) & 57.9 & (1.5) & 58.2 & $(1.5)$ & 59.0 & $(1.6)$ & 60.0 & $(1.6)$ \\
\hline Fiorentina & 51 & 55.0 & (1.3) & 55.9 & (1.3) & 55.3 & (1.3) & 53.9 & (1.4) & 53.2 & $(1.5)$ \\
\hline Genoa & 51 & 53.9 & $(1.0)$ & 54.8 & (1.1) & 55.2 & (1.1) & 55.5 & $(1.2)$ & 55.2 & $(1.2)$ \\
\hline Lazio & 66 & 52.3 & $(2.7)$ & 53.5 & (2.6) & 53.9 & $(2.6)$ & 54.9 & (2.7) & 56.0 & (2.7) \\
\hline Palermo & 56 & 49.6 & (1.1) & 50.5 & (1.2) & 50.9 & $(1.2)$ & 51.7 & $(1.2)$ & 52.6 & (1.3) \\
\hline Parma & 46 & 48.9 & (1.3) & 49.8 & (1.3) & 50.2 & (1.3) & 50.9 & (1.4) & 50.7 & (1.4) \\
\hline Sampdoria & 36 & 48.2 & $(1.5)$ & 49.0 & $(1.6)$ & 46.5 & $(1.6)$ & 43.5 & (1.7) & 41.2 & (2.1) \\
\hline Lecce & 41 & 45.6 & $(1.6)$ & 46.4 & $(1.6)$ & 46.8 & (1.7) & 45.2 & (1.7) & 41.8 & (2.3) \\
\hline Bologna & 45 & 45.4 & $(1.6)$ & 46.3 & $(1.6)$ & 46.6 & (1.7) & 44.7 & $(1.8)$ & 42.4 & (2.2) \\
\hline Udinese & 66 & 44.5 & (1.4) & 45.3 & (1.5) & 45.6 & $(1.5)$ & 46.3 & $(1.5)$ & 47.3 & $(1.5)$ \\
\hline Cagliari & 45 & 42.8 & (2.1) & 43.8 & (2.1) & 44.2 & (2.1) & 45.0 & $(2.2)$ & 46.1 & (2.2) \\
\hline Cesena & 43 & 40.5 & $(1.7)$ & 41.3 & (1.7) & 41.7 & (1.7) & 42.5 & $(1.7)$ & 43.4 & (1.7) \\
\hline Catania & 46 & 39.0 & $(4.1)$ & 39.9 & $(4.0)$ & 40.3 & $(4.0)$ & 41.2 & $(4.0)$ & 42.3 & (4.1) \\
\hline Chievo & 46 & 38.9 & (1.1) & 39.8 & (1.1) & 40.1 & (1.1) & 40.9 & (1.1) & 40.8 & (1.1) \\
\hline Brescia & 32 & 37.9 & (2.2) & 38.7 & (2.2) & 39.1 & (2.2) & 39.9 & $(2.2)$ & 40.9 & (2.2) \\
\hline Bari $^{\mathrm{a}}$ & & 49.5 & $(1.2)$ & 50.2 & (1.2) & 50.4 & (1.2) & 51.0 & $(1.2)$ & 51.8 & (1.2) \\
\hline
\end{tabular}

Notes: Bootstrapped standard errors in parentheses. ${ }^{a}$ The 2011 accounts for Bari are missing, so we imputed data for the 2010 season and assumed a fixed wage bill throughout all regimes. We consequently excluded them from the calculation of the summary financial results and report their result only for completeness. 
Table A4. Points table for all FFP scenarios using O-P simulation approach, France 2011 season

\begin{tabular}{|c|c|c|c|c|c|c|c|c|c|c|c|}
\hline \multirow{2}{*}{$\frac{\text { Team }}{\text { Lyon }}$} & \multirow{2}{*}{$\begin{array}{l}\text { Real } \\
64\end{array}$} & \multicolumn{2}{|c|}{ No FFP } & \multicolumn{2}{|c|}{$€ 15 \mathrm{~m}$} & \multicolumn{2}{|c|}{$€ 10 \mathrm{~m}$} & \multicolumn{2}{|c|}{$€ 5 \mathrm{~m}$} & \multicolumn{2}{|l|}{ Final } \\
\hline & & 69.8 & (3.6) & 67.3 & (3.5) & 66.1 & (3.5) & 65.2 & (3.5) & 65.0 & \\
\hline Marseille & 68 & 69.4 & (2.6) & & (2.6) & 69.8 & (2.6) & 70.3 & (2.7) & 71.0 & \\
\hline PSG & 60 & 62.0 & (2.3) & 60.6 & (2.2) & 58.9 & (2.0) & 57.3 & (1.8) & 56.7 & \\
\hline Bordeaux & 51 & 60.5 & $(2.6)$ & & (2.6) & 60.9 & $(2.6)$ & 61.4 & (2.6) & 62.2 & \\
\hline Lille & 76 & 60.2 & (2.3) & & (2.3) & 60.5 & (2.3) & & (2.4) & 1.0 & \\
\hline uxer & 49 & 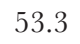 & (1.6) & 5 & $(1.6)$ & & (1.7) & & (1.7) & 1 & \\
\hline aint & 49 & 52 & $(1.5)$ & 5 & $(1$. & & $(1.5)$ & & $(1.5)$ & & \\
\hline enı & 56 & 52.7 & $(1.2)$ & 52.9 & $(1.2)$ & & (1.2) & & (1.3) & & \\
\hline Mon & 44 & 52.2 & (1.6) & 52.4 & $(1.6)$ & 52.5 & (1.6) & 5 & $(1.5)$ & 48.9 & \\
\hline Toulouse & 50 & 50.9 & $(1.5)$ & 51.1 & $(1.5)$ & 51.3 & $(1.5)$ & 5 & $(1.5)$ & 52.6 & \\
\hline $\mathrm{V}$ & 48 & 107 & (2.5) & 49.9 & $(2.5)$ & 50.0 & (2.4) & & (2.5) & & \\
\hline & 48 & & (5.3) & & (5 & & $(5.4)$ & & (5.4) & & \\
\hline $\mathrm{ccl}$ & 58 & & $(1.5)$ & & $(1.5)$ & 4 & (1.5) & 5 & (1.4) & 5( & \\
\hline aen & 46 & 47 & (2.1) & 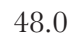 & (2.1) & 48 & (2.1) & & (2.1) & 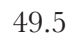 & \\
\hline Lorier & 49 & 47.4 & (3.9) & 47 & (3.9) & 47.8 & (3.9) & 48.2 & (3.9) & 49.0 & \\
\hline Montpel & 47 & 46.9 & (1.4) & 47.1 & (1.4) & 47.3 & (1.4) & 47.7 & (1.4) & 48.6 & \\
\hline Lens & 35 & 44.4 & (3.6) & 44.6 & (3.6) & 44.7 & (3.6) & 43.4 & (3.7) & 42.1 & (3 \\
\hline Nice & 46 & 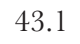 & (1.6) & 43.3 & $(1.6)$ & 43.5 & (1.5) & 43.9 & $(1.5)$ & 44.7 & \\
\hline DIt & 46 & & (1.8) & & $(1.8)$ & & $(1.8)$ & & $(1.8)$ & & $(1$ \\
\hline Arles & 20 & 28.3 & (2.2) & 28.5 & (2.2) & 28.6 & (2.2) & 29.1 & (2.1) & 30.0 & \\
\hline
\end{tabular}

Note: Bootstrapped standard errors in parentheses.

\section{A3. Simulation approach}

We broadly outline the simulation procedure in the paper. In more detail, we go through the following steps.

1. For each team where $b_{i t}<b_{i t}^{F F P}$ : change $p_{i t}^{*}$ to $p_{i t}^{\prime}=p_{i t}^{*}+\left(b_{i t}-b_{i t}^{F F P}\right)$

2. Using $p_{i t}^{\prime} \forall i$, recalculate the points totals, $w_{i t}^{\prime}$, and revenues, $r_{i t}^{\prime}$.

3. Adjust $p_{i t}^{\prime}$ to the new revenues, setting

a. if the team owner follows the "profit"-objective:

$$
\begin{aligned}
& \text { i. } p_{i t}^{\prime \prime}=p_{i t}^{\prime}+\left(r_{i t}^{\prime}-r_{i t}^{*}\right) \text { if } p_{i t}^{\prime}<p_{i t}^{*} \\
& \text { ii. } p_{i t}^{\prime \prime}=p_{i t}^{*} \text { otherwise. }
\end{aligned}
$$

b. if the team owner follows the "win"-objective: $p_{i t}^{\prime \prime}=p_{i t}^{\prime}+\left(r_{i t}^{\prime}-r_{i t}^{*}\right)$ for all teams.

4. Repeat step 2 and 3 until the difference in simulated points $w_{i t}^{\prime \prime}-w_{i t}^{\prime}<\theta, \forall i$, where $\theta$ is a predefined threshold, which we set at 0.1 points

We report the results for a homogeneous league of either win- or profit-oriented owners in the paper. These are two special cases of a more general model, whereby heterogeneous owner objectives may exist, with some 'profit' and other 'win' oriented owners in the league. It is important to understand how the reported results in terms of average wage, revenue, wtto and competitive balance relate to the full distribution 
of possible simulation outcomes. For each league and regime we therefore generate 1,000 simulations of mixed leagues, randomly selecting teams to behave as win- or profit-oriented each time. As an example Figure Al depicts these results for the $€ 15$ million regime in England, but results for other regimes and leagues are completely similar. The dashed line depicts the 'win'-maximizing league, the dot and dash line the 'profit'-maximizing scenario. We clearly see that the reported scenarios are the extreme cases in terms of average wage and wtto, which supports their use to judge the rent shifting effects of the break-even rule. For average revenues and competitive balance, the reported scenarios are not on the edges of the distribution, which implies that more extreme results are possible. We would indeed expect to see a larger point spread if some 'win'-maximizing owners of large market teams are pitched against 'profit'-oriented owners for the smaller teams. Revenues on the other hand are very sensitive to the team specific effects estimated in Equation (2) and consequently to the identity of the teams, which gain more points.

To calculate the standard errors shown in parentheses in the simulation tables, we bootstrap our simulations of the baseline scenarios using 200 independent draws from the joint distribution of all estimated parameters. As a test case to examine whether the fixed point we find is unique over a broader range of starting values for payrolls or merely a local extreme value, we repeat the exercise described in Appendix section Al for the $€ 15$ million regime in England. As with the laissez-faire equilibrium we found the same fixed point for all draws of the initial payrolls.

\section{REFERENCES}

American Needle, Inc. v. National Football League, 560 (The Supreme Court May 24, 2010).

Ascari, G. and P. Gagnepain (2006). 'Spanish football', Journal of Sports Economics, 7, 76-89.

Borland, J. and R. MacDonald (2003). 'Demand for sport', Oxford Review of Economic Policy, 19 (4), 478-502.

Chester, N. (1968). Report of the Committee on Football for the Department of Education and Science, London: HMSO.

Dietl, H. M., M. Lang and A. Rathke (2009). 'The effect of salary caps in professional team sports on social welfare', The B.E. Fournal of Economic Analysis and Policy, 9(1), 1935-682.

Dupont, J.-L. (2013). Press release, 6 May.

Foot, J. (2010). Calcio: A History of Italian Football, London: Harper Perennial.

Forrest, D. and R. Simmons (2002). 'Team salaries and playing success in sports: a comparative perspective', Zeitschrift fü Betriebswirtschaft, 4.

Fort, R. and J. Quirk (1995). 'Cross-subsidization, incentives, and outcomes in professional team sports leagues', Foumal of Economic Literature, 33(3), 1265-99.

Franck, E. and M. Lang (2012). 'What is wrong with Sugar Daddies in football? A theoretical analysis of the influence of money injections on risk-taking', University of Zurich, Center for Research in Sports Administration, Working Paper 46.

Garcia, J. and P. Rodriguez (2002). 'The determinants of football match attendance revisited', Fournal of Sports Economics, 3(1), 18-38.

Garicano, L., I. Palacios-Huerta and C. Prendergast (2005). 'Favoritism under social pressure', Review of Economics and Statistics, 87(2), 208-16.

Gouguet, J.-J. and D. Primault (2006). 'The French exception', Fournal of Sports Economics, 7, $47-59$. 
Hoehn, T. and S. Szymanski (1999). 'The Americanization of European football', Economic Policy, 14(28), 203-40.

Késenne, S. (2000). 'The impact of salary caps in professional team sports', Scottish Fournal of Political Economy, 47(4), 422-30.

Madden, P. (forthcoming). 'Welfare economics of "Financial Fair Play" in a sports league with benefactor owners', Journal of Sports Economics.

Müller, J. C., J. Lammert and G. Hovemann (2012). 'The Financial Fair Play Regulations of UEFA: An adequate concept to ensure the long-term viability and sustainability of European club football?' International Fournal of Sport Finance, 7(2), 117-40.

Olley, S. and A. Pakes (1996). 'The dynamics of productivity in the telecommunications equipment industry', Econometrica, 64(6), 1263-97.

Rivers, D. and Q. H. Vuong (1988). 'Limited information estimators and exogeneity tests for simultaneous probit models', Journal of Econometrics, 39, 347-66.

Roberts, G. R. (1984). 'Sports Leagues and the Sherman Act: the use and abuse of Section A to regulate restraints on intraleague rivalry', UCLA Law Review, 32, 219-301.

Rottenberg, S. (1956). 'The baseball players' labor market', Fournal of Political Economy, 64(3), $242-58$.

Szymanski, S. (2001). 'Income inequality, competitive balance and the attractiveness of team sports: some evidence and a natural experiment from English soccer', Economic Fournal, 111 , 69-84.

- (2003). 'The economic design of sporting contests', Fournal of Economic Literature, 41(4), $1137-87$.

- (2012). 'Insolvency in English football: irrational exuberance or negative productivity shocks?' International Association of Sports Economists \& North American Association of Sports Economists, Working Paper 1202.

Szymanski, S. and R. Smith (1997). 'The English football industry: profit, performance and industrial structure', International Review of Applied Economics, 11(1), 135-53.

Union of European Football Associations (UEFA) (2012a). Club Licensing Benchmarking Report.

Union of European Football Associations (UEFA) (2012b). UEFA Club Licensing and Financial Fair Play Regulations, Edition 2012.

Vrooman, J. (1995). 'A general theory of professional sports leagues', Southern Economic Fournal, 61(4), 971-90. 